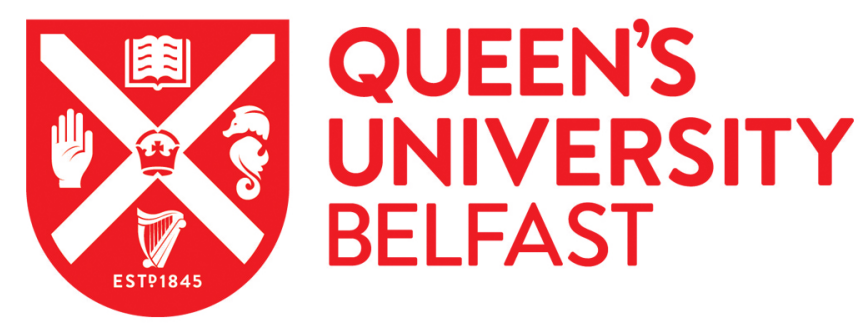

\title{
Delineation of a quick clay zone at Smørgrav, Norway, with electromagnetic methods under geotechnical constraints
}

Kalscheuer, T., Bastani, M., Donohue, S., Persson, L., Pfaffhuber, A. A., Reiser, F., \& Ren, Z. (2013).

Delineation of a quick clay zone at Smørgrav, Norway, with electromagnetic methods under geotechnical constraints. Journal of Applied Geophysics, 92, 121-136. https://doi.org/10.1016/j.jappgeo.2013.02.006

Published in:

Journal of Applied Geophysics

Document Version:

Peer reviewed version

Queen's University Belfast - Research Portal:

Link to publication record in Queen's University Belfast Research Portal

\begin{abstract}
Publisher rights
This is the author's version of a work that was accepted for publication in Journal of Applied Geophysics. Changes resulting from the publishing process, such as peer review, editing, corrections, structural formatting, and other quality control mechanisms may not be reflected in this document. Changes may have been made to this work since it was submitted for publication. A definitive version was subsequently published in Journal of Applied Geophysics, [VOL 92, (2013)]
\end{abstract}

\section{General rights}

Copyright for the publications made accessible via the Queen's University Belfast Research Portal is retained by the author(s) and / or other copyright owners and it is a condition of accessing these publications that users recognise and abide by the legal requirements associated with these rights.

Take down policy

The Research Portal is Queen's institutional repository that provides access to Queen's research output. Every effort has been made to ensure that content in the Research Portal does not infringe any person's rights, or applicable UK laws. If you discover content in the Research Portal that you believe breaches copyright or violates any law, please contact openaccess@qub.ac.uk. 


\section{Accepted Manuscript}

Delineation of a quick clay zone at Smørgrav, Norway, with electromagnetic methods under geotechnical constraints

Thomas Kalscheuer, Mehrdad Bastani, Shane Donohue, Lena Persson, Andreas A. Pfaffhuber, Fabienne Reiser, Zhengyong Ren

PII: $\quad$ S0926-9851(13)00032-3

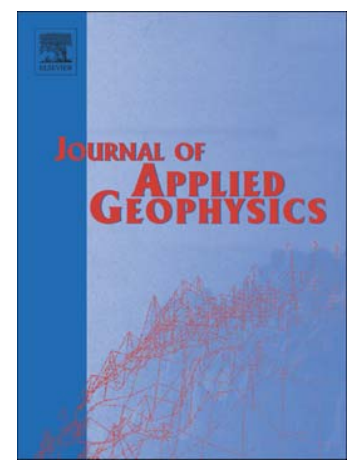

DOI: $\quad$ doi: $10.1016 /$ j.jappgeo.2013.02.006

Reference: $\quad$ APPGEO 2253

To appear in: $\quad$ Journal of Applied Geophysics

Received date: 16 July 2012

Accepted date: 4 February 2013

Please cite this article as: Kalscheuer, Thomas, Bastani, Mehrdad, Donohue, Shane, Persson, Lena, Pfaffhuber, Andreas A., Reiser, Fabienne, Ren, Zhengyong, Delineation of a quick clay zone at Smørgrav, Norway, with electromagnetic methods under geotechnical constraints, Journal of Applied Geophysics (2013), doi: 10.1016/j.jappgeo.2013.02.006

This is a PDF file of an unedited manuscript that has been accepted for publication. As a service to our customers we are providing this early version of the manuscript. The manuscript will undergo copyediting, typesetting, and review of the resulting proof before it is published in its final form. Please note that during the production process errors may be discovered which could affect the content, and all legal disclaimers that apply to the journal pertain. 


\section{Delineation of a quick clay zone at Smørgrav, Norway, with electromagnetic methods under geotechnical constraints}

Thomas Kalscheuer ${ }^{\mathrm{a}, *}$, Mehrdad Bastani ${ }^{\mathrm{b}}$, Shane Donohue ${ }^{\mathrm{c}}$, Lena Persson ${ }^{\mathrm{b}}$, Andreas A. Pfaffhuber ${ }^{\mathrm{d}}$, Fabienne Reiser ${ }^{\mathrm{a}}$, Zhengyong Ren ${ }^{\mathrm{a}}$

${ }^{a}$ Institute of Geophysics, ETH Zürich, Sonneggstr. 5, 8092 Zürich, Switzerland

${ }^{b}$ Geological Survey of Sweden, Villavägen 18, 75236 Uppsala, Sweden

${ }^{c}$ School of Planning, Architecture and Civil Engineering, Queen's University Belfast, BT9 $5 A G$, Belfast, $U K$

${ }^{d}$ Norwegian Geotechnical Institute, Sognsvn. 72, 0855 Oslo, Norway

\section{Abstract}

In many coastal areas of North America and Scandinavia, post-glacial clay sediments have emerged above sea level due to iso-static uplift. These clays are often destabilised by fresh water leaching and transformed to so-called quick clays as at the investigated area at Smørgrav, Norway. Slight mechanical disturbances of these materials may trigger landslides. Since the leaching increases the electrical resistivity of quick clay as compared to normal marine clay, the application of electromagnetic (EM) methods is of particular interest in the study of quick clay structures.

For the first time, single and joint inversions of direct-current resistivity (DCR), radiomagnetotelluric (RMT) and controlled-source audiomagnetotelluric (CSAMT) data were applied to delineate a zone of quick clay. The resulting 2-D models of electrical resistivity correlate excellently with previ-

\footnotetext{
*Corresponding author. Tel.: +41-44-6337561 Fax.: +41-44-6331065

Email address: Thomas.Kalscheuer@aug.ig.erdw.ethz.ch (Thomas Kalscheuer )
} 
ously published data from a ground conductivity metre and resistivity logs from two resistivity cone penetration tests (RCPT) into marine clay and quick clay. The RCPT log into the central part of the quick clay identifies the electrical resistivity of the quick clay structure to lie between 10 and $80 \Omega \mathrm{m}$. In combination with the $2-\mathrm{D}$ inversion models, it becomes possible to delineate the vertical and horizontal extent of the quick clay zone. As compared to the inversions of single data sets, the joint inversion model exhibits sharper resistivity contrasts and its resistivity values are more characteristic of the expected geology. In our preferred joint inversion model, there is a clear demarcation between dry soil, marine clay, quick clay and bedrock, which consists of alum shale and limestone.

Keywords: quick clay, joint inversion, radiomagnetotellurics, controlled-source audiomagnetotellurics, direct-current resistivity

1. Introduction

\subsection{Geological processes}

3 Sedimentation of clay in marine environments typically leads to highly 4 water saturated materials with a high pore volume (Bjerrum, 1954; Tor5 rance, 1974). $\mathrm{Na}^{+}$or $\mathrm{K}^{+}$cations balance the negative surface charge of clay 6 minerals in electrical double layers and, hence, allow the clay minerals to ag7 gregate in a flocculated structure. As a consequence of isostatic uplift after the end of the last ice age (at the end of the Pleistocene epoch), such marine clays were lifted above sea level in many coastal areas of Scandinavia and North America. The original pore water chemistry of these clays may have been altered as a result of the subsequent change from a marine to a fresh- 
water environment. They may have become highly sensitive to mechanical perturbation or "quick", if sufficient leaching of salt from their pore water occurred. Leaching may be caused by rainwater infiltration, diffusion and water seeping upwards through the deposit due to artesian pressure. The presence of permeable materials such as silts, sands and gravels will also increase the possibility of leaching. Disturbance of these materials may trigger a landslide during which the quick clay is remoulded and clay minerals float in their own pore fluids (Ter-Stepanian, 2000). After the landslide, most of the pore water is removed and the clay minerals are deposited in a more stable and denser configuration.

\subsection{Geophysical and geotechnical methods in the identification of quick clay}

Due to the leaching of salt, the ionic concentration of the pore water is typically reduced in quick clay. As a consequence, the electrical resistivity of quick clay is higher than that of unleached clay. The electrical resistivity of quick clay found in Norway is typically in a range of 10 to $80 \Omega \mathrm{m}$, whereas unleached clay usually has resistivities of 1 to $10 \Omega \mathrm{m}$ (Solberg et al., 2008). Consequently, the DCR method was utilised to map the distribution of electrical resistivity at quick clay sites by Solberg et al. (2008), Lundström et al. (2009) and Donohue et al. (2012). However, great care must be exercised in the interpretation of resistivity models derived from DCR or electromagnetic data, because the resistivity range of unleached clay overlaps with that of salt water intrusions and the resistivities of quick clay are similar to those of water saturated alluvium, sand, moraine, silt, fine-grained till and mudstone (e.g. Reynolds, 2011).

As the leaching also results in changes to the mechanical properties of 
quick clay, Donohue et al. (2012) investigated the multi-channel analysis of surface waves technique to distinguish quick clay from unleached clay (see below).

To overcome the ambiguity associated with the inversion of geophysical data, it is desirable to calibrate the resulting geophysical models against borehole logs or other more direct geotechnical evidence for quick clay such as rotary pressure soundings (RPS) and cone penetration tests (CPT). Rotary pressure soundings employ drill tips that are pushed into the ground at constant speed and rotation rate, thus remoulding the soil. In the drill tips, penetration resistance curves are recorded (Helle et al., 2009). Penetration resistance that decreases or stays constant with depth hints at reduced remoulded shear strength indicative of quick clay. When pushing a CPT unit into the ground at constant speed, the resistance at the tip of the cone, sleeve friction, and pore pressure behind the cone are recorded. A geotechnical instrument that was recently developed at the Norwegian Geotechnical Institute (NGI), is the resistivity cone penetration test (RCPT) (Rømoen et al., 2010). This resistivity logging system measures electrical resistivity with a four electrode array along the first extension rod behind the tip of a CPT unit.

\subsection{Study area at Smørgrav}

Figure 1 depicts a geographic map of south-eastern Norway, the location of the measurement area at Smørgrav about $55 \mathrm{~km}$ south-west of Oslo, and the distribution of known Norwegian quick clay sites (in red colour). Naturally, most quick clay sites are located along rivers and lakes. South-eastern Norway has undergone significant isostatic uplift following deglaciation of the 
region about 11000 years ago. Kenney (1964) discussed seâ-level movement and the geological history of the post-glacial marine soils in the Oslo area and concluded that this region has been rising steadily with respect to sea level and that the soils were deposited during a single period of submergence. Therefore, it would be expected that the soils were normally consolidated. At Smørgrav, the marine limit (highest post-glacial sea level) was at about $150 \mathrm{~m}$ above the present sea level (Sørensen, 1979).

In Fig. 2, we present a map of the measurement area that includes the positions of DCR profiles, RMT and CSAMT profiles, RCPT logging sites, RPS sites and boreholes relevant to this paper. The elevation of the measurement area (cf. Fig. 2) varies from about $2 \mathrm{~m}$ a.s.l. at the northwestern end at Vestfosselva river to $22 \mathrm{~m}$ a.s.l. at the south eastern end. On the first $60 \mathrm{~m}$, i.e. at the north-western end of the profile, the elevation increases by $10 \mathrm{~m}$. On the remaining part of the profile, the topographic level increases almost steadily with minor undulations of about $\pm 1 \mathrm{~m}$ in magnitude. Off the profile, differences in topographic relief are more pronounced. Most noticeable is a topographic rise of $10 \mathrm{~m}$ over a similar horizontal distance at a farm located at the south-eastern end of the profile.

Post-glacial sediments in the Smørgrav area consist predominantly of Holocene clay. According to geological maps of the Geological Survey of Norway (NGU, http://www.ngu.no), the bedrock underneath the north-western half of the profile consists of gneiss or migmatite. To the south-east, the geological map depicts geological contacts with phyllite, which has alum shale as its parent rock, and limestone. Recent salt water intrusion can be excluded as a reason for resistivities in the range of marine clays (i.e. 1 to $10 \Omega \mathrm{m}$ ), 
because the site is located inland (cf. Fig. 1).

The Geological Survey of Norway classifies the hazard level for quick clay landslides as high over an area of approximately $1.25 \mathrm{~km}^{2}$ at Smørgrav (http://www.skrednett.no). The most recent quick clay landslide at Smørgrav occurred in 1984 just $250 \mathrm{~m}$ south-west of the measurement site on the banks of Vestfosselva river.

\subsection{Previous geotechnical and geophysical results at Smørgrav}

An extensive geotechnical drilling and sampling program was conducted at the site during 2007/2008 through an NGI quick clay research program (Donohue et al., 2012). Along the main profile, RCPT resistivity and penetration resistance data are available from two core penetration tests labelled RCPT 524 and RCPT 525 through unleached and leached clay, respectively (cf. Fig. 2). At RCPT 524, low electrical resistivities below $10 \Omega \mathrm{m}$ and numerous other geotechnical tests indicates that the shallow subsurface consists of normal marine clay. At RCPT 525, penetration resistance data and electrical resistivity values above $10 \Omega \mathrm{m}$ foster the assumption that quick clay is present in a depth range from $1.5 \mathrm{~m}$ to $9 \mathrm{~m}$. At borehole BH 505 (cf. Fig. 2), an RPS and several laboratory measurements indicate the presence of quick clay at 5 to $13 \mathrm{~m}$ below ground surface (Helle et al., 2009; Donohue et al., 2012). At rotary pressure sounding RPS 506, quick clay may be present at 12 to $20 \mathrm{~m}$ depth. It should be observed that BH 505 and the RPS sites are offset by 30 to $60 \mathrm{~m}$ to the south-west of the profile, and the existence of quick clay below the profile cannot be directly inferred from the presence of quick clay in the corresponding boreholes. 
Donohue et al. (2012) interpret a comprehensive geophysical data set collected at Smørgrav in November 2008 with DCR, coil-coil frequency-domain electromagnetic (FDEM), seismic refraction and surface wave methods.

DCR data were measured with two partly overlapping Wenner arrays (designated as DCR Wenner 1 and DCR Wenner 2 in Fig. 2) and an electrode spacing of $5 \mathrm{~m}$ (Donohue et al., 2012). Each Wenner array had a length of $160 \mathrm{~m}$ and the two Wenner arrays overlapped by $45 \mathrm{~m}$. Hence, the total length of the electrode spread was $275 \mathrm{~m}$. The inversion model of this DCR data set (more detail in the sections below) is in good agreement with the RCPT resistivity at RCPT 524 and RCPT 525 (Donohue et al., 2012).

FDEM data were collected with a Geonics EM-31 coil-coil system. The apparent conductivity responses (Frischknecht et al., 1991) are depicted in Fig. 3 and support the interpretation that quick clay may be present in a wider area around RCPT 525 (Donohue et al., 2012). For clarity, we draw the DCR gradient profile (see below) in red and labels for profile metres $y$ employed henceforth in Fig. 3. Abnormal FDEM response functions at $y=70 \mathrm{~m}$ along the profile and data gaps at $y=200 \mathrm{~m}$ along the profile are caused by an underground cable and a fence, respectively.

Multi-channel analysis of surface waves indicate a slight decrease of seismic S-wave velocities in the potential quick clay structure, whereas the refraction analysis of P-waves was predominantly successful in identifying shallow bedrock in the south-eastern part of the measurement area (Donohue et al., 2012). 


\subsection{Recent DCR, RMT and CSAMT surveys at Smørgrav}

To overcome the limited penetration depth in the middle of the combined Wenner arrays of Donohue et al. (2012), additional DCR data were collected with a Schlumberger gradient array and $5 \mathrm{~m}$ electrode spacing in November 2010. The length of the electrode spread employed in the latter campaign was $370 \mathrm{~m}$ (designated by DCR gradient in Fig. 2). The start point of this new electrode array is offset by $68 \mathrm{~m}$ towards the north-west of the start point of the previous Wenner arrays.

Tensorial RMT data were measured in the frequency range between 14 and $226 \mathrm{kHz}$ and at 35 stations with a spacing of $10 \mathrm{~m}$ using the EnviroMT system (Bastani, 2001). The start point of this profile is offset by $40 \mathrm{~m}$ towards the north-west of the start point of the DCR Wenner arrays of Donohue et al. (2012). To obtain a greater depth of penetration than with the RMT data alone, controlled-source audio-magnetotelluric (CSAMT) data were recorded at six frequencies between 2 and $12.5 \mathrm{kHz}$ employing a pair of perpendicular horizontal magnetic dipole sources at a distance of $310 \mathrm{~m}$ from the profile (cf. Fig. 2). The main purposes of the RMT and CSAMT measurements were to delineate the structural bounds of the quick clay formation (in particular the deeper boundary) and to obtain a more detailed description of the distribution of electrical resistivity from joint inversions with DCR data. 


\section{Theory}

\subsection{DCR method}

The direct-current resistivity method (Daily et al., 2005; Zonge et al., 2005 ) is an active method, where two current electrodes are employed to inject a temporally constant current $I$ into the subsurface. With two additional potential electrodes, a potential difference or voltage $U$ is measured. This voltage depends on the injected current $I$, the positions of the current and potential electrodes as well as the distribution of electrical resistivity $\rho$ in the subsurface. Typically, DCR data are depicted as pseudo-sections of apparent resistivities

$$
\rho_{a}=K \frac{U}{I}
$$

where $K$ is a geometric factor that depends on the positions of current and potential electrodes. Often, apparent resistivities are plotted against the midpoints of the electrode configurations on the horizontal axis and electrode separation dependent factors on the vertical axis (Edwards, 1977). Physically, the apparent resistivity is a weighted average of the distribution of electrical resistivity in the subsurface around the electrodes. For a homogeneous half-space, it equals the half-space resistivity. To reach greater depth, electrode separations need to be increased.

\subsection{RMT method}

The radiomagnetotelluric method (Tezkan et al., 1996, 2005; Newman et al., 2003; Pedersen et al., 2005; Bastani et al., 2011) is a passive electromagnetic method that employs the signals from remote radio transmitters in the VLF and LF frequency bands between 10 and $300 \mathrm{kHz}$. Due to the 
large distance to the radio transmitters, the EM fields incident at a receiver site can be considered as uniform inducing fields or plane waves. On the surface both horizontal components of the electric field $\left(E_{x}, E_{y}\right)$ and all three components of the magnetic field $\left(H_{x}, H_{y}, H_{z}\right)$ are recorded. The resulting time series are then processed to yield two tensors of complex valued transfer functions in the frequency domain:

- The impedance tensor $\mathbf{Z}$ relates the horizontal magnetic to the horizontal electric fields as (Bastani and Pedersen, 2001; Berdichevsky and Dmitriev, 2008)

$$
\left[\begin{array}{c}
E_{x} \\
E_{y}
\end{array}\right]=\left[\begin{array}{cc}
Z_{x x} & Z_{x y} \\
Z_{y x} & Z_{y y}
\end{array}\right]\left[\begin{array}{c}
H_{x} \\
H_{y}
\end{array}\right] .
$$

In the case of a 2-D subsurface with the $x$-axis oriented along the geological strike direction, $Z_{x x}=Z_{y y}=0$, the impedance tensor element $Z_{x y}$ arises due to current flow along the strike direction (so called transverse-electric mode or TE-mode), and $Z_{y x}$ is related to current flow in the plane of the profile (so called transverse-magnetic mode or TM-mode).

The determinant impedance $Z_{D}=\sqrt{Z_{x x} Z_{y y}-Z_{x y} Z_{y x}}$ is independent of the horizontal directions of the geographic reference system and tends to yield inversion models that are less affected by 3-D structures off the profile than models from the inversion of TE-mode or TM-mode data (Pedersen and Engels, 2005).

Typically, the complex impedance tensor elements $Z_{i j}$ are transformed 
to apparent resistivities

$$
\rho_{a}^{i j}=\frac{1}{\omega \mu_{0}}\left|Z_{i j}\right|^{2}
$$

and phases

$$
\phi^{i j}=\arg \left(Z_{i j}\right) \text {, }
$$

where $\omega=2 \pi f$ is the angular frequency of the EM field, and $\mu_{0}$ is the magnetic permeability of free space.

- The tensor of vertical magnetic transfer functions (VMTF) $\left[\begin{array}{ll}A & B\end{array}\right]$ relates the vertical component of the magnetic field to the horizontal magnetic field components as (Bastani and Pedersen, 2001; Berdichevsky and Dmitriev, 2008)

$$
H_{z}=A \cdot H_{x}+B \cdot H_{y}
$$

The estimation of standard deviations of the impedance tensor elements and the VMTFs is described in detail by Bastani and Pedersen (2001).

The depth at which the amplitude of the EM field is reduced to $1 / e$ of its amplitude at the surface defines the skin depth

$$
\delta=\sqrt{\frac{2 \bar{\rho}}{\omega \mu_{0}}},
$$

of the uniform inducing field, where $\bar{\rho}$ is an effective or average resistivity of the subsurface (Spies, 1989). Depending on noise conditions and instrumental accuracy, the maximal depth of investigation $z_{\max }$ scales with the skin depth of the plane wave or uniform inducing field as $z_{\max } \approx 1.5 \delta$ to $2.0 \delta$ (Spies, 1989). 


\subsection{CSAMT method}

The CSAMT method (Zonge and Hughes, 1991) employs grounded cables or closed loops of wire as aerials to actively transmit signals at a number of fixed frequencies. The typical frequency range employed in this method is $1 \mathrm{~Hz}$ to $10 \mathrm{kHz}$. To obtain fully tensorial transfer functions as for the RMT method (cf. eqs. 2 and 5), pairs of perpendicularly oriented grounded cables or closed loops with horizontal axes are used as sources ( $\mathrm{Li}$ and Pedersen, 1991). At distances of more than five times the (side-)length of the transmitter aerials, controlled-source fields are typically treated as such of horizontal electric dipoles (HED) or horizontal magnetic dipoles (HMD), respectively. At source-receiver distances of more than five to ten times the local skin depth (eq. 6) of a uniform inducing field of the same frequency, the 3-D curvature of CSAMT source fields can be neglected and the CSAMT transfer functions can be modelled as such of uniform inducing fields (cf. sec. 2.2).

As CSAMT frequencies are typically smaller than RMT frequencies, the maximal depth of investigation is increased, when CSAMT data are recorded in addition to RMT data. However, at source-receiver distances on the order of magnitude of the uniform inducing field skin depth or smaller, the effective CSAMT skin depth also depends on the source-receiver geometry.

\subsection{Inverse modelling}

In the inverse modelling process, a model vector $\mathbf{m}$ of electrical resistivities is sought that generates a vector $\mathbf{F}[\mathbf{m}]$ of $N_{d}$ modelled forward responses which are similar to $N_{d}$ measured data stored in a vector $\mathbf{d}$ (Menke, 1989). Here, the entries of $\mathbf{d}$ and $\mathbf{F}[\mathbf{m}]$ can be the apparent resistivities $\rho_{a}^{i j}$ and phases $\phi^{i j}$ of the RMT or CSAMT impedance tensor $\mathbf{Z}$ or determinant 
impedance $Z_{D}$, the RMT or CSAMT VMTF $\left[\begin{array}{ll}A & B\end{array}\right]$ or the apparent resistivities $\rho_{a}$ of the DCR method. The goodness of fit of the forward responses to the field data is measured as a misfit $Q_{d}$ (essentially a $\chi^{2}$ error) or a root-mean-square (RMS) error

$$
\begin{aligned}
Q_{d} & =(\mathbf{d}-\mathbf{F}[\mathbf{m}])^{T} \mathbf{W}_{d}^{T} \mathbf{W}_{d}(\mathbf{d}-\mathbf{F}[\mathbf{m}]), \\
R M S & =\sqrt{\frac{1}{N_{d}} Q_{d}},
\end{aligned}
$$

where the diagonal matrix $\mathbf{W}_{d}$ contains the reciprocal errors of the measured data d. If the data errors are true, an RMS error of 1.0 is typically considered optimal, because it signifies good data fit without fitting too much to noise. Datum-wise relative misfits depicted in the following sections are computed as $\left(d_{i}-F_{i}[\mathbf{m}]\right) / \sigma_{i}$ for $i=1, \ldots, N_{d}$.

A model parameter vector $\mathbf{m}$ that minimises the misfit $Q_{d}$ is computed by demanding that the gradient of $Q_{d}$ w.r.t. $\mathbf{m}$ vanishes. As the forward operator $\mathbf{F}[\mathbf{m}]$ is non-linear in $\mathbf{m}$, the minimisation of $Q_{d}$ is performed iteratively through a Taylor series expansion of $\mathbf{F}[\mathbf{m}]$ to first order in $\mathbf{m}$ (Menke, 1989) yielding a quadratic approximation to $Q_{d}$. Since we compute forward responses on a 2-D finite-difference mesh (cf. Kalscheuer et al., 2010), there need to be far more model cells than data points to obtain sufficiently accurate forward modelling results. Furthermore, EM inverse problems are inherently non-unique and ill-posed. Hence, to invert for an Earth model of electrical resistivity additional constraints have to be imposed on the model (Menke, 1989). These additional constraints are implemented by adding further terms of model regularisation to eq. 7. Here, two types of model regularisation are employed. First, the semblance (often referred to as smoothness) of the resistivities of abutting cells of the inversion model is imposed 
through smoothness constraints (de Groot-Hedlin and Constable, 1990). Second, a Marquardt-Levenberg damping term that demands small changes to the model of the previous iteration (Lines and Treitel, 1984) is introduced. In a purely smoothness-constrained inversion, convergence problems still can occur, because the quadratic approximation to $Q_{d}$ is not sufficiently accurate yielding a false prediction of the model that minimises $Q_{d}$ (Rodi and Mackie, 2001) and the smoothness constraints define a semi-norm without a unique minimum. Marquardt-Levenberg damping effectively enforces convergence, because high damping can be employed to yield a model update in the steepest descent direction of $Q_{d}$ (Lines and Treitel, 1984).

In total, we minimise an unconstrained cost functional

$$
\begin{aligned}
U\left[\mathbf{m}_{k+1}, \lambda\right]= & \left(\mathbf{d}-\mathbf{F}\left[\mathbf{m}_{k+1}\right]\right)^{T} \mathbf{W}_{d}^{T} \mathbf{W}_{d}\left(\mathbf{d}-\mathbf{F}\left[\mathbf{m}_{k+1}\right]\right) \\
& +\lambda\left(\mathbf{m}_{k+1}-\mathbf{m}_{r}\right)^{T} \mathbf{W}_{m}^{T} \mathbf{W}_{m}\left(\mathbf{m}_{k+1}-\mathbf{m}_{r}\right) \\
& +\beta\left(\mathbf{m}_{k+1}-\mathbf{m}_{k}\right)^{T}\left(\mathbf{m}_{k+1}-\mathbf{m}_{k}\right)
\end{aligned}
$$

w.r.t. the model parameters $\mathbf{m}_{k+1}$ of the $(k+1)$-th iteration. In eq. $9, \lambda$ is a Lagrange multiplier for the smoothness constraints $\mathbf{W}_{m}^{T} \mathbf{W}_{m}=\alpha_{y} \partial_{y}^{T} \partial_{y}+$ $\alpha_{z} \partial_{z}^{T} \partial_{z}$, in which $\partial_{y}$ and $\partial_{z}$ are matrices of horizontal and vertical smoothness operators, respectively, weighted through factors $\alpha_{y}$ and $\alpha_{z}$. The vector $\mathbf{m}_{r}$ is an optional reference model. The Lagrange multiplier $\lambda$ is determined in a trial-and-error procedure to yield $R M S \gtrsim 1$. An optimal damping factor $\beta$ of the Marquardt-Levenberg term (the last term on the r.h.s. of eq. 9) is determined in each iteration with a line search. More details on the joint inversion of DCR and RMT data, in particular the iterative computation of an inversion model $\mathbf{m}$ from the cost functional in eq. 9, can be found in 
Candansayar and Tezkan (2008) and Kalscheuer et al. (2010).

Due to differences in a) the number of data employed from different methods, b) the sensitivities of the different methods, c) the non-linear nature of the corresponding forward problems, or d) the quality of data error estimates, it typically is necessary to assign weights to individual data sets to avoid one data set being more dominant than the other data sets in the joint inversion (Athanasiou et al., 2007; Candansayar and Tezkan, 2008; Commer and Newman, 2009; Kalscheuer et al., 2010; Bastani et al., 2012). When the number of DCR data is much higher than the number of RMT data, for instance, DCR data are typically over-fitted and RMT data are under-fitted resulting in inversion models that may contain erroneous structures from noise in the DCR data. The weights are typically implemented as factors on the data errors in $\mathbf{W}_{d}$. Synthetic modelling studies with manual weighting of DCR and RMT data were presented by Candansayar and Tezkan (2008) and Kalscheuer et al. (2010). In the weighting scheme used by Kalscheuer et al. (2010), weighting leads the optimal RMS to differ from 1.0. In Appendix A, we describe different schemes for data weighting and introduce a new scaling mechanism that yields optimal RMS errors of 1.0 for both individual and combined data sets in the presence of weighting.

To analyse our inversion models, we compute linearised model resolving kernels and error estimates according to Kalscheuer et al. (2010) that account for the smoothness constraints employed in the inversion. Assuming that the forward response of the model of the $k$-th iteration is linearly close to that of the true model, Kalscheuer et al. (2010) derive a relationship to analyse, how the true model $\mathbf{m}^{\text {true }}$, the reference model $\mathbf{m}_{r}$, and noise $\mathbf{n}$ contained in 
the data map into the model $\mathbf{m}_{k+1}$ of the $k+1$-th iteration:

$$
\mathbf{m}_{k+1} \approx \mathbf{R}_{M} \mathbf{m}^{\text {true }}+\left(\mathbf{I}-\mathbf{R}_{M}\right) \mathbf{m}_{r}+\mathbf{J}_{\mathbf{W}}^{-g} \mathbf{W}_{d} \mathbf{n}
$$

where $\mathbf{R}_{M}=\mathbf{J}_{\mathbf{W}}^{-g} \mathbf{J}_{\mathbf{W}}$ is the model resolution matrix, $\mathbf{J}_{\mathbf{W}}^{-g}=\left[\mathbf{J}^{T} \mathbf{W}_{d}^{T} \mathbf{W}_{d} \mathbf{J}+\lambda \mathbf{W}_{m}^{T} \mathbf{W}_{m}\right]^{-1} \mathbf{J}^{T} \mathbf{W}_{d}^{T}$ is the generalised inverse, and $\mathbf{J}$ is the sensitivity matrix of partial derivatives of the forward response $\mathbf{F}\left[\mathbf{m}_{k}\right]$ w.r.t. the model parameters $\mathbf{m}_{k}$. The $i$-th row of $\mathbf{R}_{M}$ describes the contribution that the true model has to the $i$-th parameter of $\mathbf{m}_{k+1}$. The smaller the spread of non-zero entries of the $i$-th row of $\mathbf{R}_{M}$ around the diagonal entry $R_{M, i i}$ is and the higher $R_{M, i i}$ is, the better is $m_{k+1, i}$ resolved by the data. To render the model resolution estimates less dependent on the sizes $\Delta y_{j}$ and $\Delta z_{l}$ of the cells of the finite-difference mesh in horizontal and vertical directions, we investigate resolving kernels $r_{M, i(j l)}=R_{M, i(j l)} /\left(\Delta y_{j} \Delta z_{l}\right)$ which can be reckoned a resolution density. To estimate, how strong the effect of variability in the reference model and noise $\mathbf{n}$ in the data is on the estimated model $\mathbf{m}_{k+1}$, a linearised model covariance matrix is deduced from eq. 10 as (Menke, 1989; Kalscheuer et al., 2010)

$$
\left[\operatorname{cov} \mathbf{m}_{k+1}\right] \approx\left(\mathbf{I}-\mathbf{R}_{M}\right)\left[\operatorname{cov} \mathbf{m}_{r}\right]\left(\mathbf{I}-\mathbf{R}_{M}\right)^{T}+\mathbf{J}_{\mathbf{W}}^{-g} \mathbf{J}_{\mathbf{W}}^{-g^{T}}
$$

The covariance matrix of the reference model is $\left[\operatorname{cov} \mathbf{m}_{r}\right]=\left(\lambda \mathbf{W}_{m}^{T} \mathbf{W}_{m}\right)^{-1}$. For non-stochastic inversion schemes such as our smoothness-constrained scheme, $\mathbf{m}_{r}$ is typically considered a fixed vector and, hence, $\left[\operatorname{cov} \mathbf{m}_{r}\right]=0$. We state model error estimates solely w.r.t. the second term in eq. 11 . The square root of the $i$-th diagonal entry of eq. (11) yields the error (standard deviation) of the $i$-th model parameter. In the inversion, logarithmic cell 
resistivities are employed as model parameters. Errors of these logarithmic resistivities relate to error factors $f$ on resistivities corresponding to ranges $[\rho / f, f \rho]$ for $68 \%$ confidence intervals.

\section{Results}

\subsection{Topographic effects}

Since the employed inversion algorithm assumes a flat surface topography, we evaluate topographic effects on the field data with other forward and inverse modelling codes and select data for inversion that exhibit the least topographic effect. Topographic effects on the data can be expected from variation of relief both along the profile and off the profile (cf. sec. 1.3). Important changes in topographic relief are a) a change in slope at position $y=0 \mathrm{~m}$ along the profile, b) an elevational difference of almost $10 \mathrm{~m}$ over a comparable lateral distance close to the south-eastern end of the profile and c) a topographic low due to a stream at a distance of 30 to $80 \mathrm{~m}$ to the north of the profile (cf. Fig. 2).

Topographic effects on DCR data were previously investigated by Tsourlos et al. (1999), Rücker et al. (2006), Günther et al. (2006), and Demirci et al. (2012). We estimate the effect of topography on the DCR gradient data by comparing 2-D inversion models (not shown) computed with the 2-D finite-element code by Günther et al. (2006) assuming a) a flat air-Earth interface and b) topography as present along the profile. These inversion models differ locally by up to $20 \%$ in resistivity. To the largest part, these differences occur at depth and can be attributed to differing model discretisation and regularisation. Also, negligence of topography did not introduce 
additional structures to the inversion model. Hence, we do not reckon these differences severe enough to invalidate a flat surface as an assumption in modelling the DCR data.

Baranwal et al. (2011) investigated the effect of neglecting topography in the inversion of RMT data. For smaller topographic undulations that cover a height difference of a few metres over a couple of tens of metres or more the expected distortion is rather small. To quantify topographic effects on the RMT data collected at Smørgrav, Ren et al. (2013) applied a boundary-element modelling (BEM) code that simulates RMT fields on arbitrary topography under the assumption of constant material parameters. A digital elevation model for the Smørgrav area was generated from the topographic map in Fig. 2. The RMT transfer functions were computed for a local co-ordinate system $(u, v, n)$ that is aligned with topography. Here, the $u$ and $v$ directions are perpendicular and parallel to the profile, respectively, corresponding to the $x$ and $y$ directions of our flat Earth model; $n$ is directed normal to the Earth' surface. The strongest topographic effect was found to stem from the topographic rise off the south-eastern end of the profile. Ren et al. (2013) found the determinant impedance to be far less affected by topographic effects than the $Z_{v u}$ or $Z_{u v}$ impedances. For a $3000 \Omega \mathrm{m}$ medium with the given topography, the apparent resistivities and phases of the determinant impedance vary by up to $14 \%$ and 2.25 degrees, respectively, around the constant values of $3000 \Omega \mathrm{m}$ and 45 degrees, respectively, of a homogeneous half-space. In contrast, the $Z_{v u}$ and $Z_{u v}$ impedances have deviations of up to $27 \%$ and 2.5 degrees for apparent resistivity and phase, respectively. For a $30 \Omega \mathrm{m}$ medium, the apparent resistivities and phases of the determi- 
nant impedance deviate by up to $10 \%$ and 1.6 degrees, respectively, from the values of a homogeneous half-space.

\subsection{Inversion of DCR data}

The DCR apparent resistivities measured with the two abutting Wenner arrays employed by Donohue et al. (2012) are depicted in Fig. 4(a). The data are plotted at the horizontal centre point of each Wenner measurement and versus the effective depth $z_{e}$ defined in Edwards (1977). No errors for DCR measurement were estimated, such that the relative error of the apparent resistivities was chosen as $3 \%$ and the absolute error for $U / I$ was selected as $0.001 \Omega$. In preliminary inversions, data associated with electrodes at $y=0 \mathrm{~m}$ and $y=80 \mathrm{~m}$ persistently had high misfits, indicating coupling problems. Hence, data employing these electrodes were excluded from further inversions. In addition, individual measurements that had high misfits were excluded.

The inversion model for the edited Wenner data is shown in Fig. 4(b) together with the RCPT logging results of boreholes 524 and 525. The inversion process employed smoothing weights $\alpha_{y}=4$ and $\alpha_{z}=1$ and yielded an RMS error of 0.96. Variation of the horizontal smoothing weight $\alpha_{y}$ in the range from 1 to 6 yielded models with similar RMS errors.

The DCR data collected with the gradient array are plotted in Fig. 5(a) according to the convention proposed by Dahlin and Zhou (2006), i.e. there is one panel for each midpoint factor $m$. However, for data with $m=0$ the employed electrode configuration is essentially a Wenner-Schlumberger array and the convention by Dahlin and Zhou (2006) can result in plotting different data at the same position. Hence, we utilise the plotting convention 
of Wenner-Schlumberger data by Edwards (1977) for gradient data with $m=$ 0. Consequently, in Fig. 5(a), it should be observed that the effective depth $z_{e}$ for $m=0$ stems from a different definition than the ones for $m=-3, \ldots,-1$, and $m=1, \ldots, 3$.

The model for the DCR gradient data is depicted in Fig. 5(b) together with the RCPT logging results of boreholes 524 and 525. The inversion process utilised smoothing weights $\alpha_{y}=4$ and $\alpha_{z}=1$ resulting in an RMS error of 1.00 .

Both DCR inversion models are in excellent agreement with the RCPT resistivity logs.

\subsection{Inversion of RMT and CSAMT data}

The RMT and CSAMT field data in form of apparent resistivities and phases for the TM-mode, TE-mode and determinant impedances are depicted in Fig. 6. In order to avoid erroneous model structures, five stations in the vicinity of the buried cable and one station at the fence (cf. Fig. 3) had to be excluded from further analysis and inverse modelling. The CSAMT standard deviations as computed with the scheme by Bastani (2001) often exceed $3 \%$ and $2.5^{\circ}$ for apparent resistivity and phase, respectively, indicating that the CSAMT data are contaminated with relatively strong noise. In contrast, the standard deviations of the RMT apparent resistivities and phases hardly exceed these values.

In the inversion of CSAMT data with a 2-D inversion code for MT and RMT data, it is assumed that the distance to the source is sufficiently large that the electromagnetic fields impinging upon the Earth at the receiver sites can be approximated as uniform inducing fields or plane waves, i.e. that the 
receiver is not located in the near-zone or transition-zone of the transmitter (Zonge and Hughes, 1991). Violation of this presupposition results in erroneous inversion models. As a first assessment of possible source effects on the CSAMT data, apparent resistivities and phases of the determinant impedance are plotted against frequency in Fig. 7 for four stations. If source effects were negligible, the transfer functions would be entirely smooth at the transition from RMT to CSAMT frequencies. In the apparent resistivity plots, the transitions are very smooth. The phase curves show rougher transitions with relatively noisy readings between 10 and $14 \mathrm{kHz}$. This has two reasons. First, at CSAMT frequencies of 10 and $12.5 \mathrm{kHz}$, transfer functions are sometimes unstable due to the tuning of the transmitter system. Second, at many sites the number of VLF transmitters used in the RMT processing is relatively low at the lowest VLF frequencies of about $14 \mathrm{kHz}$, rendering transfer functions at these frequencies slightly unstable. Depending on the azimuthal distribution of the received VLF transmitters, this effect can also be directionally dependent. To conclude, we do not judge source effects from the CSAMT transmitter to be evident at the transition between the RMT and CSAMT frequency ranges. A quantitative evaluation of potential source effects over the entire CSAMT frequency range is given in one of the following paragraphs.

Bastani and Persson (2009) performed a strike analysis of the RMT and CSAMT impedance tensor data utilising the galvanic distortion analysis by Zhang et al. (1987). For the north-western half of the profile, varying the strike angle between 0 and 90 degrees resulted in very similar and small misfits of the distortion model essentially suggesting 1-D conditions. On 
the south-eastern half of the profile, the RMT and CSAMT data suggest a north-south trending geological strike direction. To facilitate joint inversion with DCR data, we selected the determinant impedance data as RMT and CSAMT data for the following inversions (cf. sec. 2.2). The effect of an incorrectly chosen profile direction is largely mitigated through the rotational invariance of determinant impedance data (Pedersen and Engels, 2005). Furthermore, we demonstrated in sec. 3.1 that the topographic effect on the determinant impedances is smaller than that on the $Z_{x y}$ or $Z_{y x}$ impedances and we hope to avoid artefacts in our models by inverting determinant impedances.

In accordance with our above assessment, error floors of $15 \%$ relative error and $2.28^{\circ}$ absolute error were assumed for apparent resistivities and phases, respectively, to mitigate topographic effects on the inversion models. The inversion model for the inversion of RMT determinant impedances only is depicted in Fig. 8(a). Employing smoothing weights $\alpha_{y}=4$ and $\alpha_{z}=1$, the model fits the RMT data to RMS=1.01, whereas additional tests with horizontal weights of $\alpha_{y}=2$ or $\alpha_{y}=6$ led to increased RMS errors. The model in Fig. 8(a) indicates a conductive structure at depths of more than $20 \mathrm{~m}$ in the middle of the profile and with resistivities of 1 to $2 \Omega \mathrm{m}$. Upon inclusion of the CSAMT determinant impedances in the inverse modelling (cf. Fig. 8(b), RMS = 1.09), the depth of investigation is increased and the conductive structure is reproduced in more detail. Its resistivity is less than $0.5 \Omega \mathrm{m}$ and is present at $y \gtrsim 100 \mathrm{~m}$. It is noteworthy, that this conductive structure is not observed in the DCR inversion models (Figs. 4(b) and 5(b)) due to the limited depth of penetration of the injected direct current systems. 
In both inversions, datum-wise RMS errors are highest for the high-frequency RMT apparent resistivities at the south-eastern end of the profile. In accordance with the BEM results by Ren et al. (2013), we assume that the steep slope off the south-eastern end of the profile (height difference of $10 \mathrm{~m}$ over $10 \mathrm{~m}$ distance, cf. Fig. 2) leads to distortion of the high frequency data.

To further validate our modelling assumption that the CSAMT data from Smørgrav can be modelled as transfer functions due to uniform inducing fields, we compare forward responses computed under the uniform inducing field assumption with those resulting from a pair of HMDs for a 1-D model from a vertical resistivity section of our 2-D model. From the model in Fig. 8(b), we chose the resistivity section below the station at $y=200 \mathrm{~m}$, because the high resistivity underneath this receiver site would yield the most pronounced effect of the HMD sources (cf. Zonge and Hughes, 1991). In modelling the responses of the HMD sources, we utilised the same sourcereceiver geometry as in the field. The responses for both source mechanisms were computed with the code by Kalscheuer et al. (2012) and are shown in Fig. 9. The responses of the main impedance tensor elements $Z_{x y}$ and $Z_{y x}$ for both source mechanisms are in excellent agreement. Furthermore, the absolute values of the diagonal impedance tensor elements for the controlled source field are almost three orders of magnitude smaller than those of the main (off-diagonal) impedance tensor elements, and the absolute values of the VMTFs are not larger than 0.13. Hence, the assumption of a uniform inducing field is perfectly justifiable in the inversion of determinant impedance data. 


\subsection{Joint inversion of DCR, RMT and CSAMT data}

Following the findings of the individual inversions of DCR and RMT/CSAMT data, we utilised the same smoothing weights, i.e. $\alpha_{y}=4$ and $\alpha_{z}=1$, in the joint inversions.

Fig. 10(a) shows the model from a 2-D joint inversion of the DCR Wenner data (Fig. 4(a)) and the RMT data (Fig. 6), i.e. CSAMT data were not included. Data weights (cf. Appendix A) of $1 / w_{\mathrm{RMT}}=1 / w_{\mathrm{DCR}}=1.0$ of the RMT and the DCR data led to RMS misfits of 1.44 and and 1.35 for the DCR and RMT data sets, respectively. Data fits to the RMT and DCR field data are depicted in Figs. 10(b) and 10(c), respectively. As compared to the models of individual inversions of the DCR Wenner and RMT data in Figs. 4(b) and 8(a), respectively, the joint inversion model exhibits sharper resistivity contrasts and a higher resistivity (of about $3000 \Omega \mathrm{m}$ ) of the resistive structure underneath the south-eastern third of the profile at $y \gtrsim 150 \mathrm{~m}$ and $z=5 \mathrm{~m}$ to $20 \mathrm{~m}$. It was previously observed by Candansayar and Tezkan (2008) and Kalscheuer et al. (2010), that joint inversions of DCR and RMT data yield better constrained resistive structures than individual inversions.

After several trial inversions, it was found that a weighting of $1 / w_{\text {RMT\&CSAMT }}=$ 1.4 to $1 / w_{\mathrm{DCR}}=1.0$ of the $\mathrm{RMT} / \mathrm{CSAMT}$ data relative to the DCR gradient data led to an RMS of 1.32 for the DCR data set and to an RMS of 1.22 for the RMT/CSAMT data. The joint inversion model for this set of weights is depicted in Fig. 11(a). Datum-wise fits of the model responses to the DCR and RMT/CSAMT field data are depicted in Figs. 11(b) and 11(c), respectively. As compared to the individual inversion of RMT and CSAMT data (Fig. 8(b)) and the joint inversion model of DCR Wenner and RMT data 
(Fig. 10(a)), the joint inversion model of DCR gradient and RMT/CSAMT data suggests that the deep conductive structure at $z \gtrsim 20 \mathrm{~m}$ is laterally homogeneous underneath the south-eastern half of the profile and has resistivities of about $0.3 \Omega \mathrm{m}$. The structure off the south-eastern end of the profile at $y \geq 300 \mathrm{~m}$ with resistivities in excess of $4000 \Omega \mathrm{m}$ was shown to be poorly constrained by the data. According to forward modelling tests, neither the fit to the DCR data nor the fit to the RMT and CSAMT data is adversely affected, if the resistivity of this structure is decreased to $1000 \Omega \mathrm{m}$ or if it becomes less vertically extended.

We evaluate the stability and uniqueness of the joint inversion model in Fig. 11(a) with the linearised model error and resolution analysis introduced in sec. 2.4. The resistivities of seven cells labelled A through G in Fig. 11(a) were selected for analysis. Cells A through $\mathrm{C}$ are located in possible quick clay structures. Cell D is located in the highly resistive formation, cell $\mathrm{E}$ is part of the deep conductive structure, cell F lies in a possible north-western continuation of this deep conductor, and cell $\mathrm{G}$ pertains to a highly resistive structure just off the south-eastern end of the profile. The positions and extents of the cells as well as the linearised model errors $f$ are listed in Table 1, and the resolving kernels are depicted in Fig. 12. For all parameters, the error factors $f$ are smaller than 1.13 indicating a stable inversion model. Since cells A to $\mathrm{C}$ are positioned in a depth range down to $15 \mathrm{~m}$ below the central part of the profile, their resistivities are fairly well resolved. Given the relatively shallow depth of $8.7 \mathrm{~m}$ to the centre of cell $\mathrm{B}$, the corresponding resolving kernel is quite strongly spread and smooth. The reason for this is that RMT data from stations above cell $\mathrm{B}$ were removed from the inversion due to noise 
effects form the buried cable (cf. sec. 3.3). Due to the highly complementary information in galvanically coupled DCR data and inductively coupled RMT data for resistive structures, the resolving kernel for cell D in the highly resistive formation is focused around cell D. In contrast, the resolving kernel for cell $\mathrm{E}$ in the upper part of the deep conductor is more spread. This larger spread can be attributed to the greater depth and the fact that the CSAMT data which mostly constrain this conductor are relatively noisy. To investigate a possible north-western continuation of this deep conductor, we consider the resolving kernel of cell F. Clearly, only small entries of the resolving kernel are found in cell $F$ and the surrounding cells. Hence, this part of the model is not resolved by the data and we can neither corroborate nor dismiss a continuation of the deep conductor to the north-west. For cell G underneath the south-eastern end of the profile, constraints provided by the DCR data are negligible and apparent resistivity and phase of the RMT and CSAMT data are hardly changed by the resistive structure. In support of the findings of our forward modelling tests, resolving kernel elements of significant amplitude are spread over the very shallow subsurface and the resistivity of the true model at the position of cell $\mathrm{F}$ hardly maps into the resistivity of cell $\mathrm{F}$ in the inversion model.

\section{Geological interpretation}

In Fig. 13, a geological interpretation of the joint inversion model in Fig. 11 is presented. In accordance with the RCPT logging results, shallow structures in the north-western half of the profile at 1 to $10 \Omega \mathrm{m}$ are interpreted as marine (i.e. unleached) clay. In the central part of the profile at RCPT 
525 , a shallow structure from $3 \mathrm{~m}$ to about $15 \mathrm{~m}$ depth, with an extension of about $130 \mathrm{~m}$ along the profile and with a resistivity of 10 to $80 \Omega \mathrm{m}$ (e.g. cells B and C in Tab. 1 and Figs. 11 and 12) is assumed to consist of quick clay. At around $\mathrm{y}=0 \mathrm{~m}$ in a depth range between $12 \mathrm{~m}$ and $20 \mathrm{~m}$ below ground surface, we observe resistivities between 10 and $20 \Omega \mathrm{m}$ (cell A) and interpret this structure as quick clay. This interpretation is in very good agreement with RPS 506, where quick clay was observed at 12 to $19 \mathrm{~m}$ below ground surface (Helle et al., 2009; Donohue et al., 2012).

Underneath the south-eastern third of the profile, the resistive structure at $5 \mathrm{~m}$ to $15 \mathrm{~m}$ depth and with resistivities of a few thousand Ohmmetres (cell D) is interpreted as limestone. Three limestone samples from outcrops off the south-eastern end of the profile had electrical resistivities between 3400 to $4000 \Omega \mathrm{m}$ as measured at the petrophysical laboratory of the Geological Survey of Sweden.

A highly conductive structure with resistivities below $0.5 \Omega \mathrm{m}$ is encountered at depths of about $20 \mathrm{~m}$ and more (cell E). Due to the small resistivity, this structure is reckoned alum shale (Jödicke, 1992). According to regional studies (Korja et al., 2008, and references therein), alum shales form widespread layers in the Scandinavian crust. It is a plausible assumption, that alum shale is present also at depth underneath the north-western half of the profile. Due to the conductive unleached clay, current channelling and skin effect lead to a diminished depth of penetration for the DCR and RMT/CSAMT methods, respectively, and based on the DCR, RMT and CSAMT data no statement can be made on a north-western continuation of the alum shale or a possible transition to migmatite as expected according 
to geological maps of the area.

A feature that is common to both of our joint inversion models (Figs. 10 and 11 ) is that the resistivity at $10 \mathrm{~m}$ depth is no longer in as good agreement with the resistivity log at RCPT 525 as in the individual inversions. Forward modelling demonstrated that the increased resistivity of about $100 \Omega \mathrm{m}$ in the 2-D joint inversion models is required to fit the DCR data whereas the RMT (and CSAMT) data can be explained with resistivities of less than $50 \Omega \mathrm{m}$ as encountered in the individual inversions. We assume this discrepancy between the individual and joint inversions to stem from anisotropy of the underlying alum shale layer which was not accounted for in the inverse modelling process. It was demonstrated by Christensen (2000) that purely galvanically coupled EM methods such as the DCR method and purely inductively coupled EM methods such as the RMT and the CSAMT method with loop sources have different anisotropic equivalencies that cannot be reconciled in joint inversions under the assumption of isotropic resistivity.

\section{Discussion and conclusions}

We presented a field example where individual and joint 2-D inversions of DCR and RMT/CSAMT data were successfully employed to delineate the geology of a quick clay site. The benefits of incorporating data from the different methods into the joint inversion and the necessity to gauge the resistivity of quick clay structures presumably encountered in the 2-D models against RCPT resistivity logs and results of other geotechnical methods were assessed.

The CSAMT data augment the RMT data to obtain a greater depth of 
investigation and to reveal the existence of a deep conductor at $z \gtrsim 20 \mathrm{~m}$ with resistivities below $0.5 \Omega \mathrm{m}$ underneath the south-eastern half of the profile (Fig. 8). This deep conductor was not previously discovered with DCR or seismic methods and most likely represents alum shale. The conductive unleached clay in the north-western half of the profile is sufficiently thick to inhibit discovery of deeper structures even at CSAMT frequencies.

The DCR data constrain the shallow part of the model down to a depth of $20 \mathrm{~m}$. Hence, the DCR data are effective in describing the resistivity section in which quick clay is expected as already observed by Donohue et al. (2012). While the inversion model of the DCR gradient data (Fig. 5(b)) vaguely indicates the existence of a deep conductor at $y \approx 120 \mathrm{~m}$ and $z \gtrsim 20 \mathrm{~m}$, its resistivity is much higher than in the inversion of the RMT and combined RMT and CSAMT data (Figs. 8(a) and 8(b), respectively) and, hence, the deep conductor might not be associated with alum shale.

In contrast to the individual inversions, the joint inversions of RMT/CSAMT and DCR data result in inversion models (Figs. 10 and 11) that are richer in detail. Our study corroborates that, in a joint inversion, RMT/CSAMT and DCR data provide constraints for resistive structures that are superior to those engaged in individual inversions. At a depth range between $5 \mathrm{~m}$ and $20 \mathrm{~m}$ on the south-eastern half of the profile, the joint inversion clearly outlines a resistive structure of about $3500 \Omega \mathrm{m}$ which in accordance with geological maps and outcrops off the south-eastern end of the profile is construed as limestone.

There is very good agreement between the 2-D models from individual inversions and the two RCPT resistivity logs located on the profile. A com- 
bination of RCPT resistivity logs and geotechnical data allows us to identify quick clay and assign a range of electrical resistivities locally representative of quick clay (10 to $80 \Omega \mathrm{m}$ in this case). Based on this knowledge, the possible location of quick clay was delineated in Fig. 13. The joint inversion models (Figs. 10 and 11) show greater variability in the electrical resistivity at RCPT 525 than the models of individual inversions and the resistivity log itself. In future investigations, it would be beneficial to investigate whether 2-D models that are locally more representative of the resistivity log can be obtained by allowing for anisotropy or by assigning the resistivity log locally as a priori information during the inversion.

\section{Acknowledgements}

The data presented in this paper were collected as part of NGI projects "SIP12 - Resistivity anisotropy in quick clay" in 2009 and "SIP12 - Procedures for quick clay mapping" in 2010 funded by the Research Council of Norway and the International Centre for Geohazards. Geotechnical and -chemical analyses at Smørgrav have been performed by Tonje Eide Helle, RCPT data were supplied by Magnus Romøen. Sara Bazin was involved in ERT data acquisition and processing in Smørgrav. 


\section{References}

\section{References}

Athanasiou, E.N., Tsourlos, P.I., Papazachos, C.B., Tsokas, G.N., 2007. Combined weighted inversion of electrical resistivity data arising from different array types. J. Appl. Geophys. 62, 124-140.

Baranwal, V.C., Franke, A., Börner, R.U., Spitzer, K., 2011. Unstructured grid based 2-D inversion of VLF data for models including topography. J. Appl. Geophys. 75, 363-372.

Bastani, M., 2001. EnviroMT - a new Controlled Source/Radio Magnetotelluric System. Ph.D. thesis. Uppsala University.

Bastani, M., Hübert, J., Kalscheuer, T., Pedersen, L.B., Godio, A., Bernard, J., 2012. 2D joint inversion of RMT and ERT data versus individual 3D inversion of full tensor RMT data: An example from Trecate site in Italy. Geophysics 77, WB233-WB243.

Bastani, M., Pedersen, L.B., 2001. Estimation of magnetotelluric transfer functions from radio transmitters. Geophysics 66, 1038-1051.

Bastani, M., Persson, L., 2009. CSRMT measurements for quick clay mapping at Smørgrav. Technical Report SGU-rapport: 08-177/2009. Geological Survey of Sweden.

Bastani, M., Savvaidis, A., Pedersen, L.B., Kalscheuer, T., 2011. CSRMT measurements in the frequency range of $1-250 \mathrm{kHz}$ to map a normal fault in the Volvi basin, Greece. J. Appl. Geophys. 75, 180-195. 
Berdichevsky, M.N., Dmitriev, V.I., 2008. Models and Methods of Magnetotellurics. Springer, Berlin and Heidelberg.

Bjerrum, L., 1954. Geotechnical properties of Norwegian marine clays. Géotechnique 4, 49-69.

Butler, D.K. (Ed.), 2005. Near-Surface Geophysics. Number 13 in Investigations in Geophysics, SEG, Tulsa.

Candansayar, M.E., Tezkan, B., 2008. Two-dimensional joint inversion of radiomagnetotelluric and direct current resistivity data. Geophys. Prospect. $56,737-749$.

Christensen, N.B., 2000. Difficulties in determining electrical anisotropy in subsurface investigations. Geophys. Prospect. 48, 1-19.

Commer, M., Newman, G.A., 2009. Three-dimensional controlled-source electromagnetic and magnetotelluric joint inversion. Geophys. J. Int. 178, $1305-1316$.

Dahlin, T., Zhou, B., 2006. Multiple-gradient array measurements for multichannel 2D resistivity imaging. Near Surf. Geophys. 4, 113-123.

Daily, W., Ramirez, A., Binley, A., LaBrecque, D., 2005. Electrical Resistance Tomography - Theory and Practice, in: Butler (2005). chapter 17. pp. $525-550$.

de Groot-Hedlin, C., Constable, S., 1990. Occam's inversion to generate smooth, two-dimensional models for magnetotelluric data. Geophysics 55, $1613-1624$. 
Demirci, I., Erdogan, E., Candansayar, M.E., 2012. Two-dimensional inversion of direct current resistivity data incorporating topography by using finite difference techniques with triangle cells: Investigation of Kera fault zone in western Crete. Geophysics 77, E67-E75.

Donohue, S., Long, M., O'Connor, P., Helle, T.E., Pfaffhuber, A.A., Rømoen, M., 2012. Multi-method geophysical mapping of quick clay. Near Surf. Geophys. 10, 207-219.

Edwards, L.S., 1977. A modified pseudosection for resistivity and IP. Geophysics 42, 1020-1036.

Frischknecht, F.C., Labson, V.F., Spies, B.R., Anderson, W.R., 1991. Profiling Methods Using Small Sources, in: Nabighian (1991). chapter 3. pp. $105-270$.

Günther, T., Rücker, C., Spitzer, K., 2006. Three-dimensional modelling and inversion of de resistivity data incorporating topography - II. Inversion. Geophys. J. Int. 166, 506-517.

Heath, M., 2002. Scientific Computing - An Introductory Survey. McGrawHill, New York. 2nd edition.

Helle, T.E., Pfaffhuber, A.A., Rømoen, M., Forsberg, C.F., 2009. SIP12 - Correlation between horizontal and vertical resistivity measurements - internal report. Technical Report NGI report 20081135-1. Norwegian Geotechnical Institute. Oslo.

Jödicke, H., 1992. Water and graphite in the Earth's crust - an approach to interpretation of conductivity models. Surv. Geophys. 13, 381-407. 
Kalscheuer, T., García, M., Meqbel, N., Pedersen, L.B., 2010. Non-linear model error and resolution properties from two-dimensional single and joint inversions of direct current resistivity and radiomagnetotelluric data. Geophys. J. Int. 182, 1174-1188.

Kalscheuer, T., Hübert, J., Kuvshinov, A., Lochbühler, T., Pedersen, L.B., 2012. A hybrid regularization scheme for the inversion of magnetotelluric data from natural and controlled sources to layer and distortion parameters. Geophysics 77, E301-E315.

Kalscheuer, T., Pedersen, L.B., 2007. A non-linear truncated SVD variance and resolution analysis of two-dimensional magnetotelluric models. Geophys. J. Int. 169, 435-447.

Kenney, T.C., 1964. Sea-level movements and the geologic histories of the post-glacial marine soils at Boston, Nicolet, Ottawa and Oslo. Géotechnique 14, 203-230.

Korja, T., Smirnov, M.Y., Pedersen, L.B., Gharibi, M., 2008. Structure of the Central Scandinavian Caledonides and the underlying Precambrian basement, new constraints from magnetotellurics. Geophys. J. Int. 175, 55-69.

Li, X., Pedersen, L.B., 1991. Controlled source tensor magnetotellurics. Geophysics 56, 1456-1461.

Lines, L.R., Treitel, S., 1984. Tutorial: A review of least-squares inversion and its application to geophysical problems. Geophys. Prospect. 32, 159 186. 
Lundström, K., Larsson, R., Dahlin, T., 2009. Mapping of quick clay formations using geotechnical and geophysical methods. Landslides 6, 1-15.

Menke, W., 1989. Geophysical data analysis: discrete inverse theory. volume 45 of International Geophysics Series. Academic Press, London.

Nabighian, M.N. (Ed.), 1991. Electromagnetic Methods in Applied Geophysics. volume 2, Applications, Parts A and B. SEG, Tulsa.

Newman, G.A., Recher, S., Tezkan, B., Neubauer, F.M., 2003. 3d inversion of a scalar radio magnetotelluric field data set. Geophysics 68, 791-802.

Pedersen, L.B., Bastani, M., Dynesius, L., 2005. Groundwater exploration using combined controlled-source and radiomagnetotelluric techniques. Geophysics 70, G8-G15.

Pedersen, L.B., Engels, M., 2005. Routine 2D inversion of magnetotelluric data using the determinant of the impedance tensor. Geophysics 70, G33G41.

Ren, Z.Y., Kalscheuer, T., Greenhalgh, S., Maurer, H., 2013. Boundary element solutions for broadband 3D geo-electromagnetic problems involving arbitrary topography accelerated by an adaptive multi-level fast multipole method. Geophys. J. Int. 192, 473-499.

Reynolds, J.M., 2011. An Introduction to Applied and Environmental Geophysics. John Wiley \& Sons Ltd, Chichester, England. 2nd edition.

Rodi, W., Mackie, R.L., 2001. Nonlinear conjugate gradients algorithm for 2-D magnetotelluric inversion. Geophysics 66, 174-187. 
Rømoen, M., Pfaffhuber, A.A., Karlsrud, K., Helle, T.E., 2010. The use of a CPTU-probe with resistivity module on marine sediments, in: CPT10: 2nd international symposium on Cone Penetration Testing, Huntington Beach, California.

Rücker, C., Günther, T., Spitzer, K., 2006. Three-dimensional modelling and inversion of dc resistivity data incorporating topography - I. Modelling. Geophys. J. Int. 166, 495-505.

Solberg, I.L., Ronning, J.S., Dalsegg, E., Hansen, L., Rokoengen, K., Sandven, R., 2008. Resistivity measurements as a tool for outlining quick-clay extent and valley-fill stratigraphy: a feasibility study from Buvika, central Norway. Can. Geotech. J. 45, 210-225.

Sørensen, R., 1979. Late Weichselian deglaciation in the Oslofjord area, south Norway. Boreas 8, 241-246.

Spies, B.R., 1989. Depth of investigation in electromagnetic sounding methods. Geophysics 54, 872-888.

Ter-Stepanian, G., 2000. Quick clay landslides: their enigmatic features and mechanism. Bull. Eng. Geol. Env. 59, 47-57.

Tezkan, B., Georgescu, P., Fauzi, U., 2005. A radiomagnetotelluric survey on an oil-contaminated area near the Brazi Refinery, Romania. Geophys. Prospect. 53, 311-323.

Tezkan, B., Goldman, M., Greinwald, S., Hördt, A., Müller, I., Neubauer, F.M., Zacher, G., 1996. A joint application of radiomagnetotellurics 
804

and transient electromagnetics to the investigation of a waste deposit in Cologne (Germany). J. Appl. Geophys. 34, 199-212.

Torrance, J.K., 1974. A laboratory investigation of the effect of leaching on the compressibility and shear strength of Norwegian marine clays. Géotechnique 24, 155-173.

Tsourlos, P.I., Szymanski, J.E., Tsokas, G.N., 1999. The effect of terrain topography on commonly used resistivity arrays. Geophysics 64, 13571363.

Zhang, P., Roberts, R.G., Pedersen, L.B., 1987. Magnetotelluric strike rules. Geophysics 52, 267-278.

Zonge, K., Wynn, J., Urquhart, S., 2005. Resistivity, Induced Polarization, and Complex Resistivity, in: Butler (2005). chapter 9. pp. 265-300.

Zonge, K.L., Hughes, L.J., 1991. Controlled Source Audio-Frequency Magnetotellurics, in: Nabighian (1991). chapter 9. pp. 713-809. 


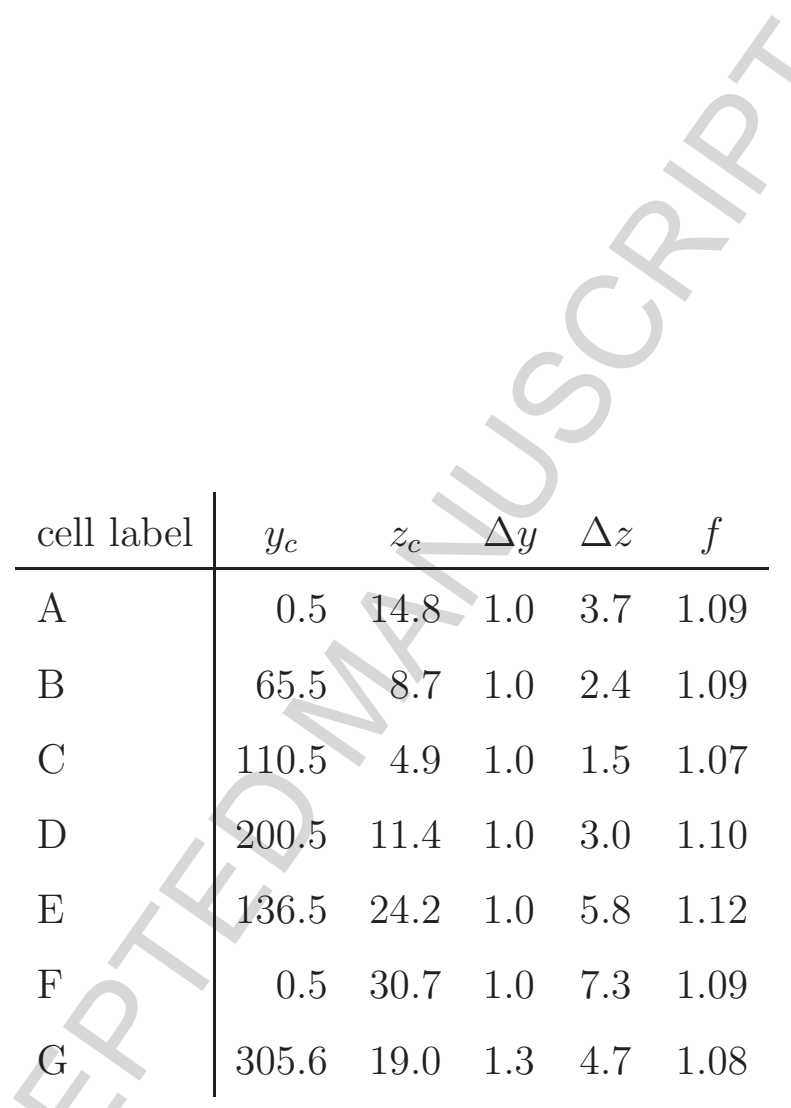

Table 1: Positions $\left(y_{c}, z_{c}\right)$ and extents $(\Delta y, \Delta z)$ of cells $\mathrm{A}$ through $\mathrm{G}$ in the inversion model in Fig. 11(a) as well as linearised error factors $f$ of the resistivities of these cells. The corresponding resolving kernels are reproduced in Fig. 12. The model error and resolution analyses were performed with the smoothness-constrained scheme by Kalscheuer et al. (2010). 


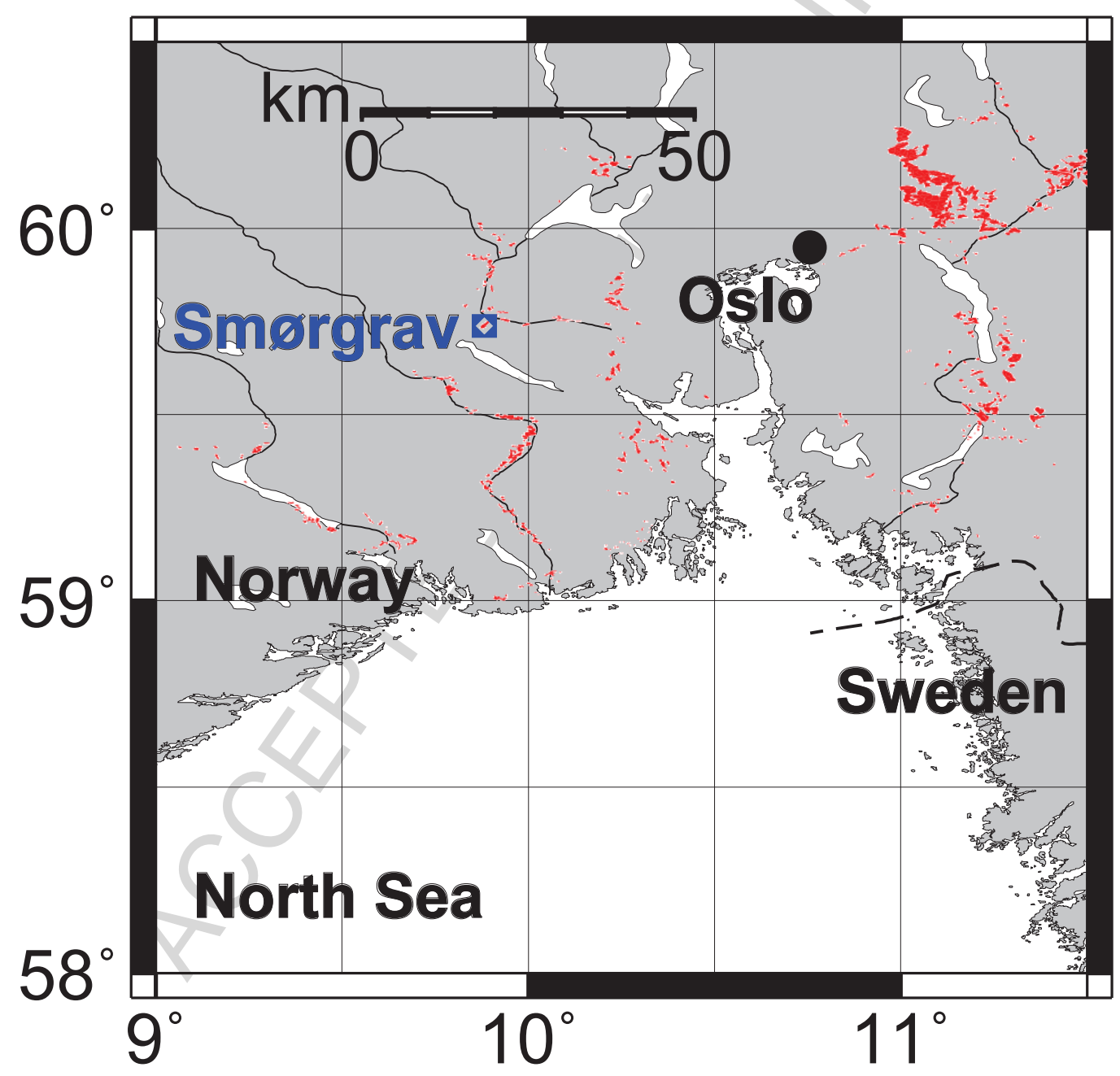

Figure 1: Geographical map of south-eastern Norway with measurement area at Smørgrav indicated by a blue square and known Norwegian quick clay sites in red colour (courtesy of Geological Survey of Norway, www.ngu.no). 


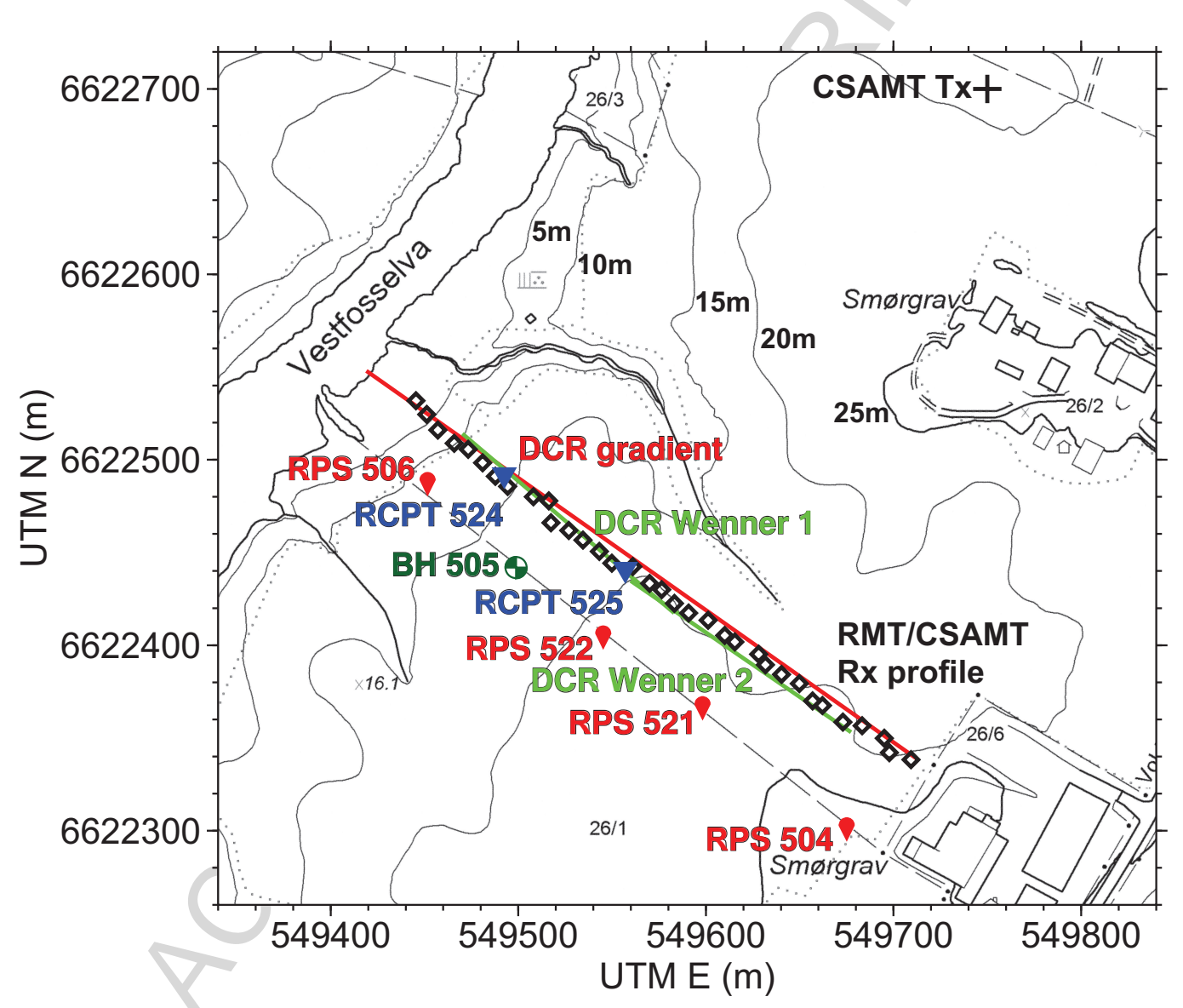

Figure 2: Measurement area at Smørgrav, with locations of RCPT logging sites (blue triangles), boreholes (dark green circles), RPS sites (dark red symbols), DCR profiles (green and red lines), RMT and CSAMT receivers (Rx, tilted black rectangles), and CSAMT transmitter (Tx) site to the north of the profile (denoted by a black cross). Topographic contour lines are at $5 \mathrm{~m}$ spacing. 


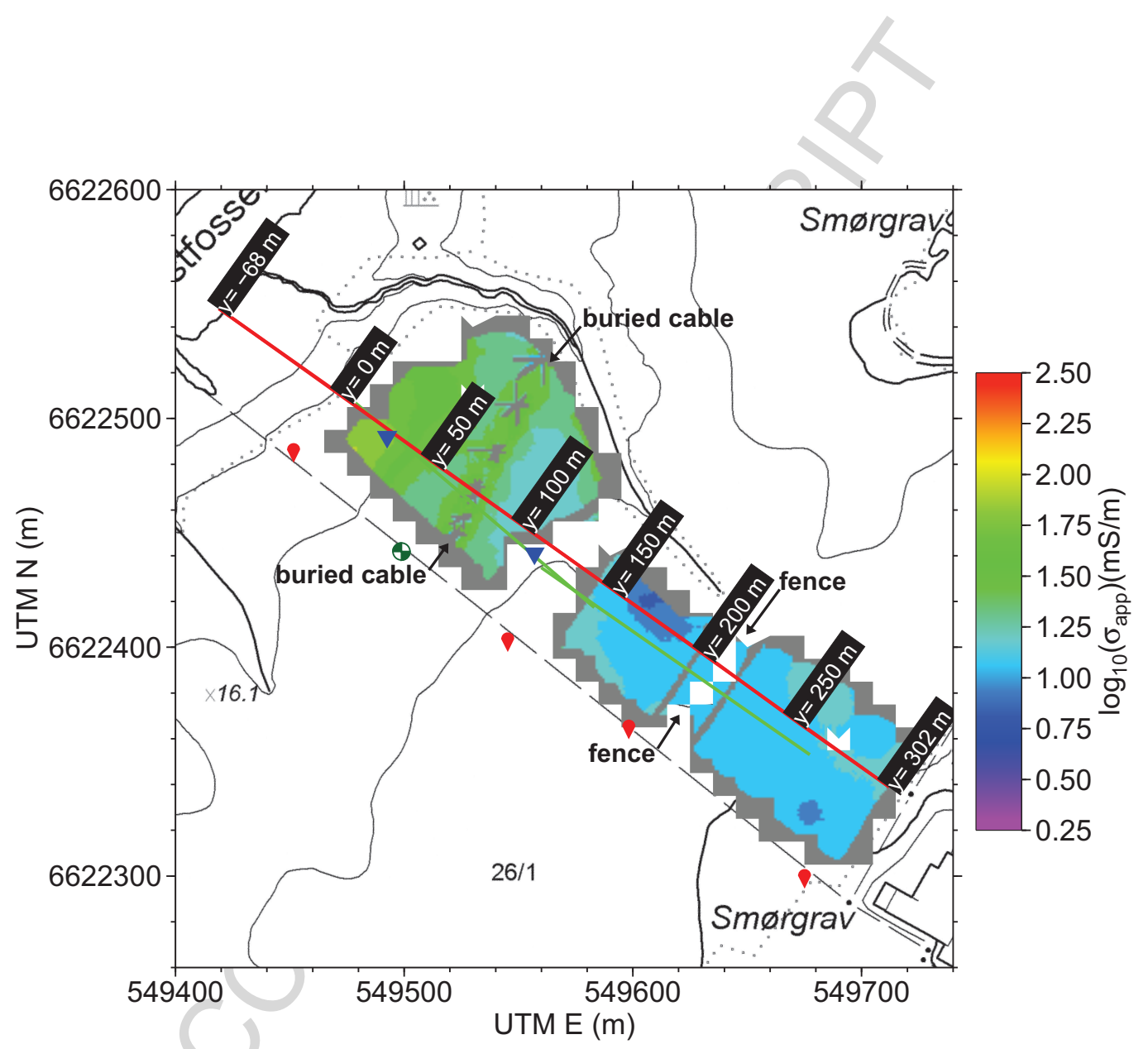

Figure 3: Apparent conductivity responses acquired with an EM-31 coil-coil FDEM system in the vertical magnetic dipole configuration by Donohue et al. (2012). The high apparent conductivity values above $30 \mathrm{mS} / \mathrm{m}$ to the north-west of the measurement area are indicative of the presence of unleached clay. The north-east to south-west tending elongated structure is a distortion effect owing to a buried cable. A data gap was caused by a fence. The red and green lines illustrate the positions of the DCR profiles (cf. Fig. 2). Labels with profile metres are plotted along the DCR gradient profile (in red). 
(a)

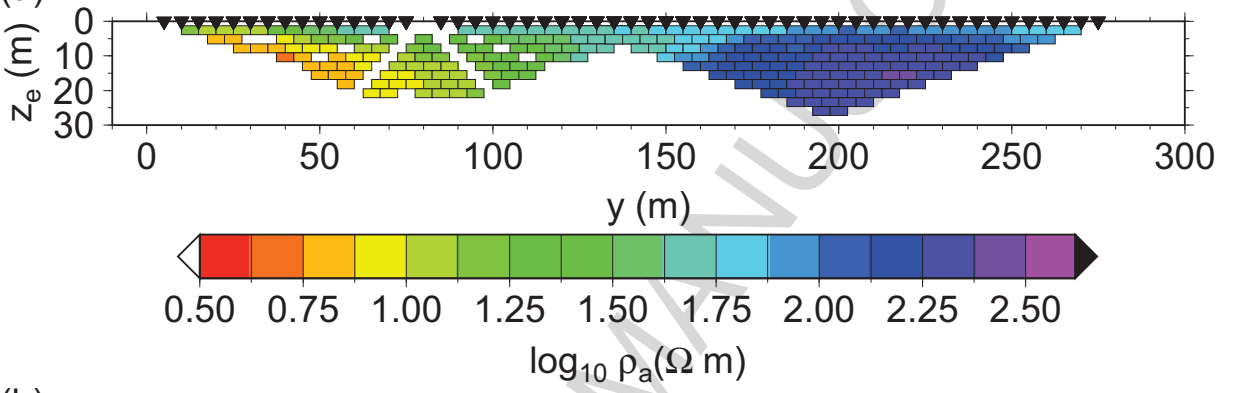

(b)

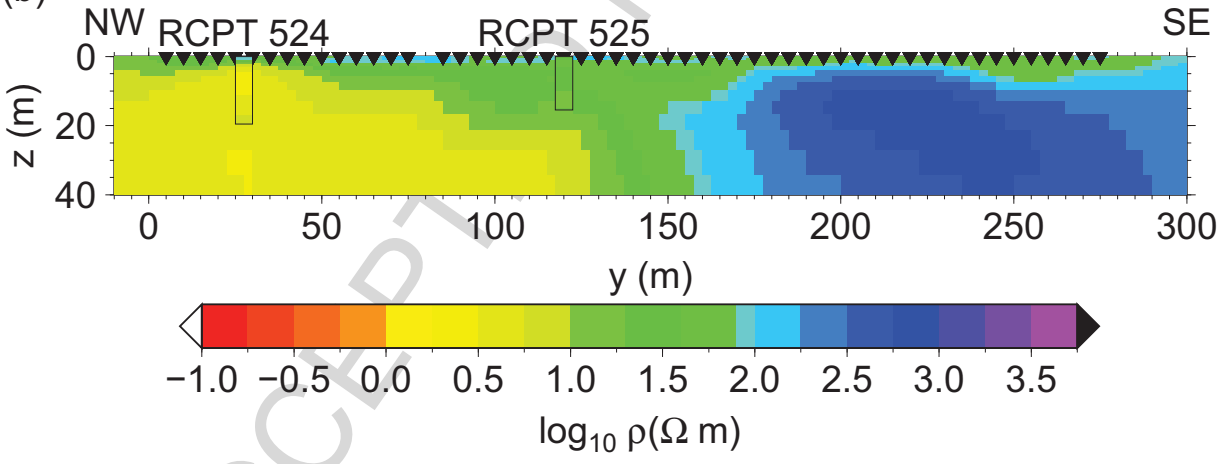

Figure 4: Edited DCR apparent resistivity data set (a) measured at Smørgrav with two abutting Wenner arrays by Donohue et al. (2012) (cf. green lines in Fig. 2) and resulting inversion model (b) plotted together with RCPT logging resistivity values at boreholes RCPT 524 and RCPT 525. The model was computed with smoothing weights $\alpha_{y}=4$ and $\alpha_{z}=1$, i.e. layered structures were preferred. The model responses fit the data to an RMS error of 0.96. Black triangles designate electrode positions. 
(a)
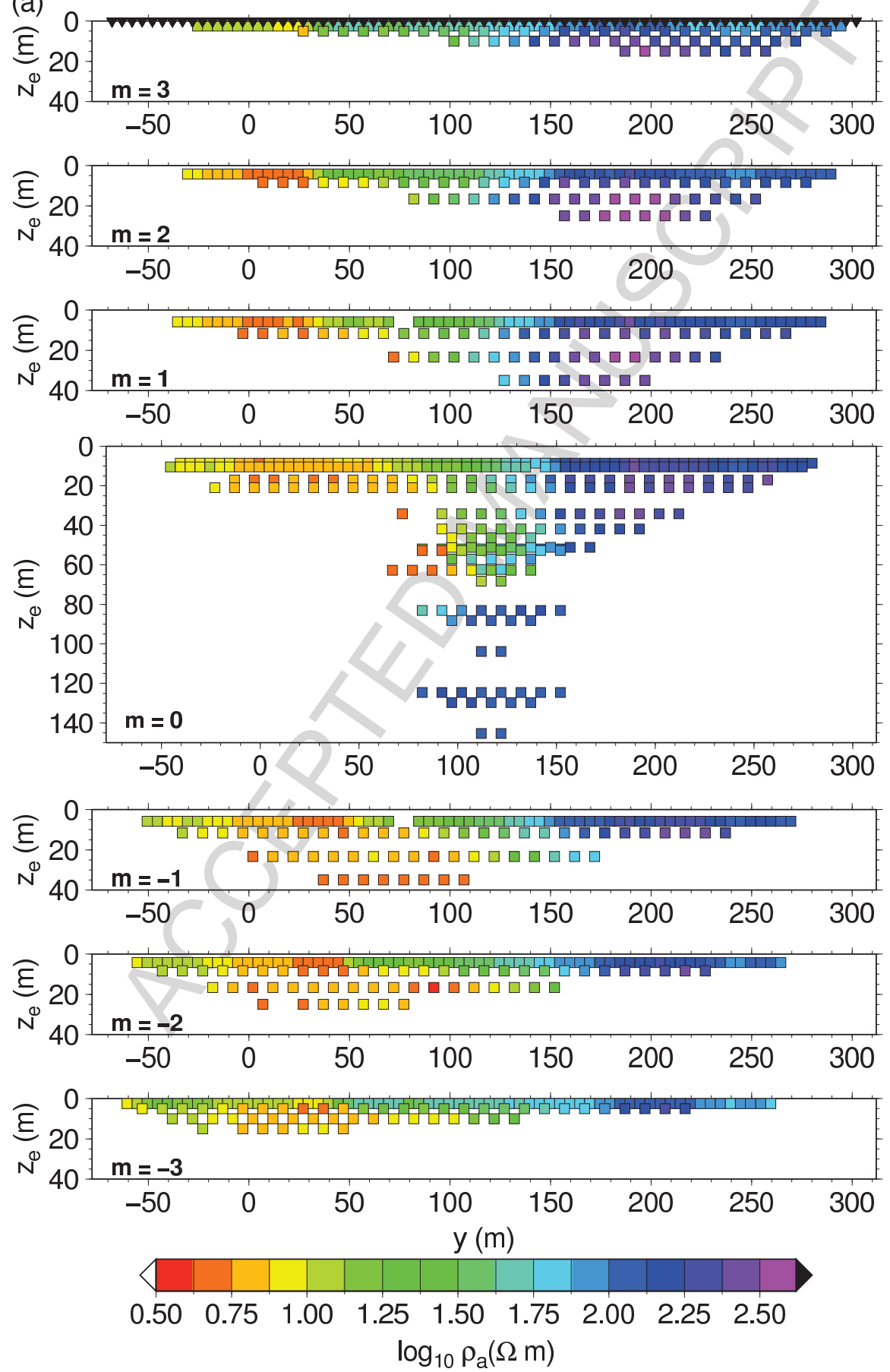

Figure 5: Apparent resistivities of edited DCR gradient data set (a) for different midpoint factors $m$ and resistivity model (b) plotted together with RCPT logging resistivity values at boreholes RCPT 524 and RCPT 525. ThABodel was computed with smoothing weights $\alpha_{y}=4$ and $\alpha_{z}=1$. The model responses fit the data to an RMS error of 1.00. Black triangles designate electrode positions. 


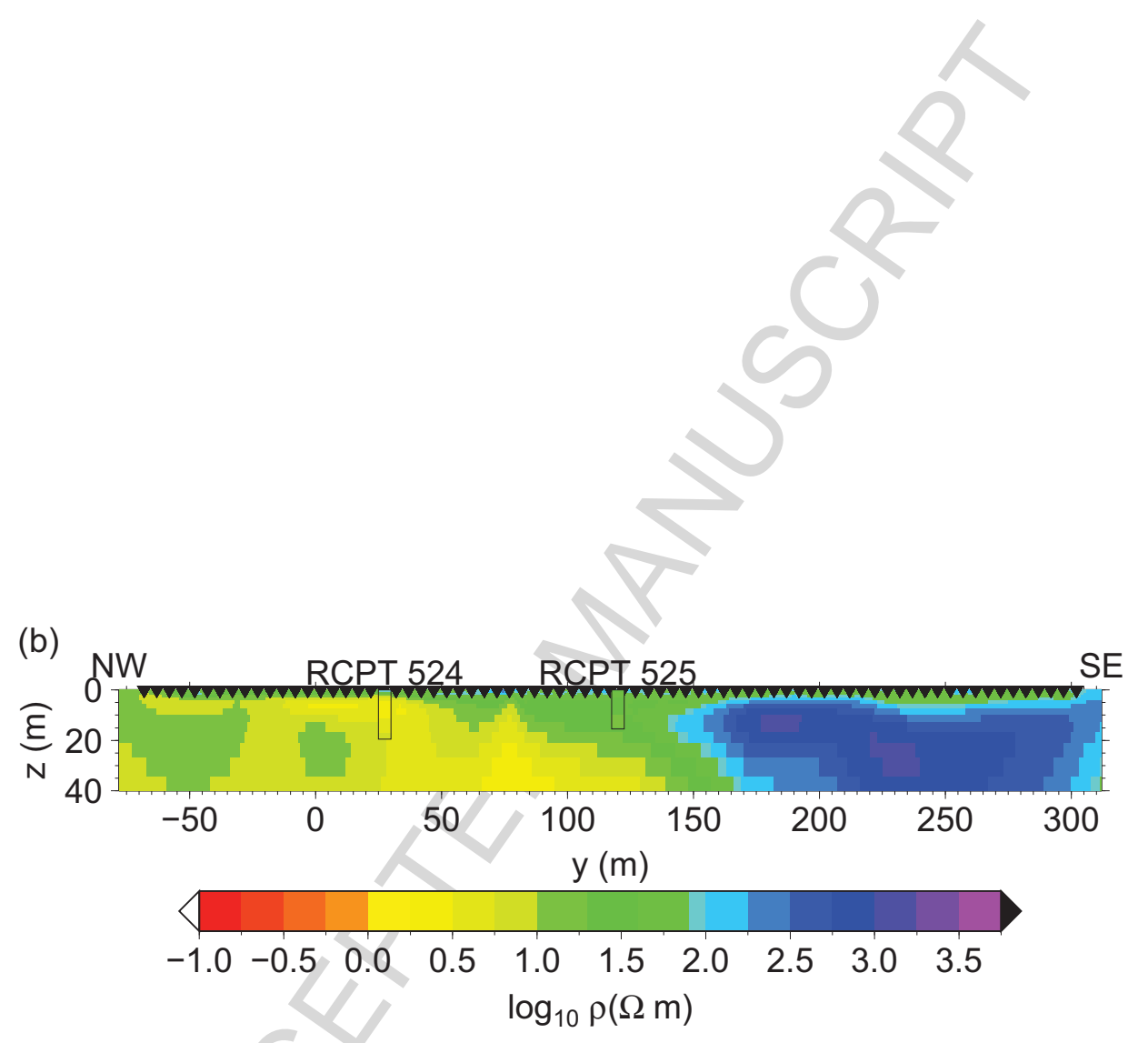

Figure 5: - continued 
(a)

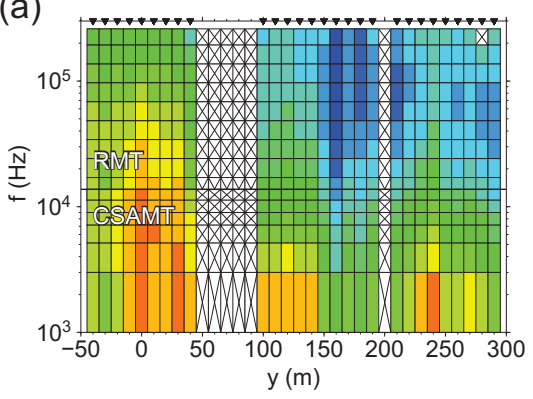

(c)

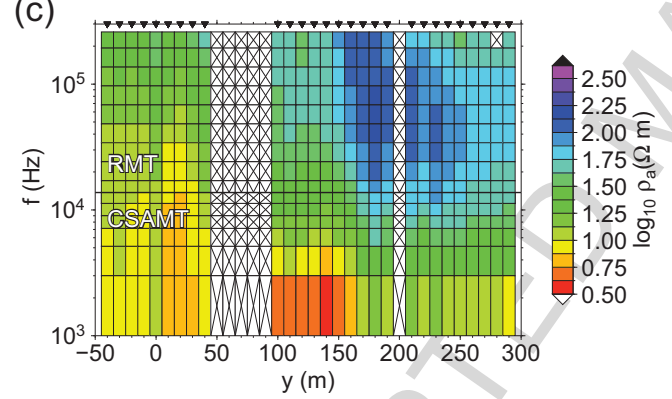

(e)

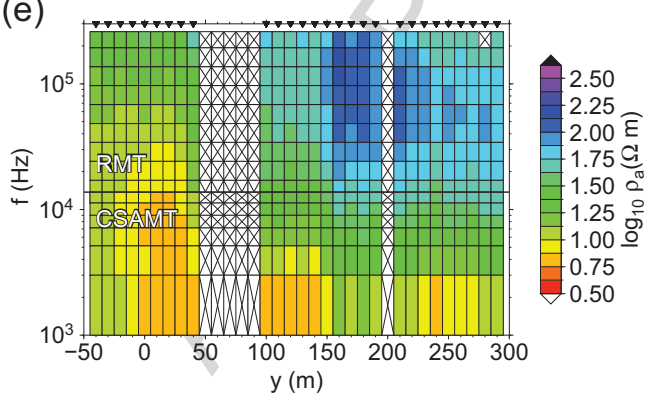

(b)

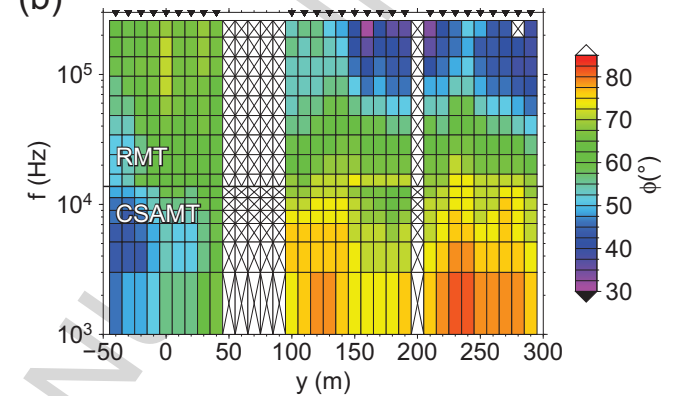

(d)

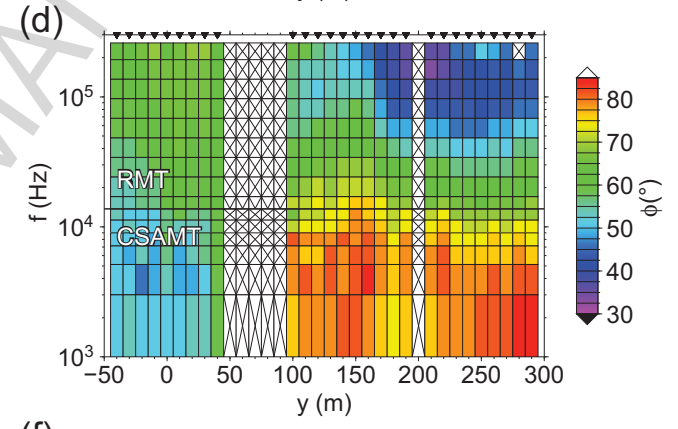

(f)

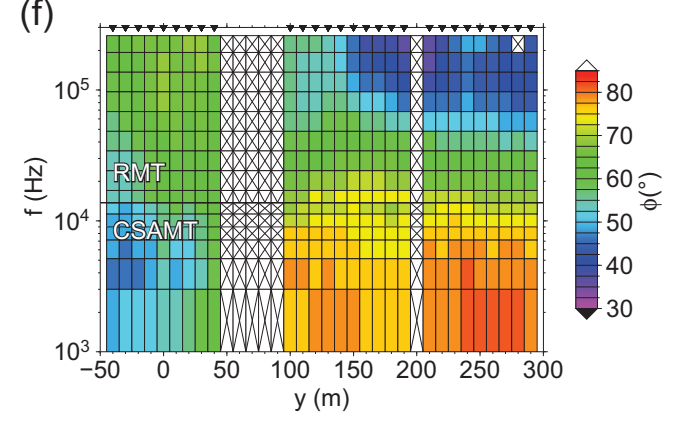

Figure 6: Edited RMT $(14-226 \mathrm{kHz})$ and CSAMT $(2-12.5 \mathrm{kHz})$ field data as apparent resistivities (left column) and phases (right column) of the $Z_{y x}$ impedances ((a) and (b)), $Z_{x y}$ impedances $((\mathrm{c})$ and $(\mathrm{d}))$ and determinant impedances ((e) and (f)). Crossed-out boxes indicate data that were removed in the editing process. Black triangles mark the positions of RMT and CSAMT receiver sites after editing. 

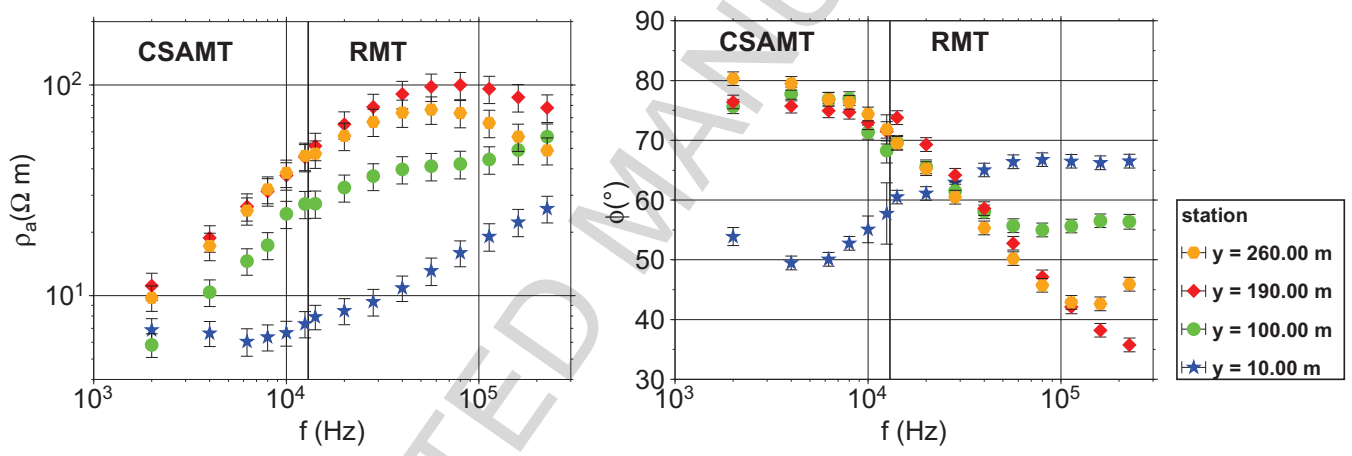

Figure 7: Apparent resistivities and phases of RMT and CSAMT determinant impedances of four stations at $y=10 \mathrm{~m}, 100 \mathrm{~m}, 190 \mathrm{~m}$, and $260 \mathrm{~m}$ along the profile. The error bars reflect the application of error floors and indicate $68 \%$ confidence levels. In particular, the apparent resistivity curves $\left(\rho_{a}\right.$, left panel) show a very smooth transition from the RMT to the CSAMT frequency range. The transition of the impedance phases ( $\phi$, right panel) is less smooth, because the CSAMT data have a higher noise level in particular at 10 and $12.5 \mathrm{kHz}$. 


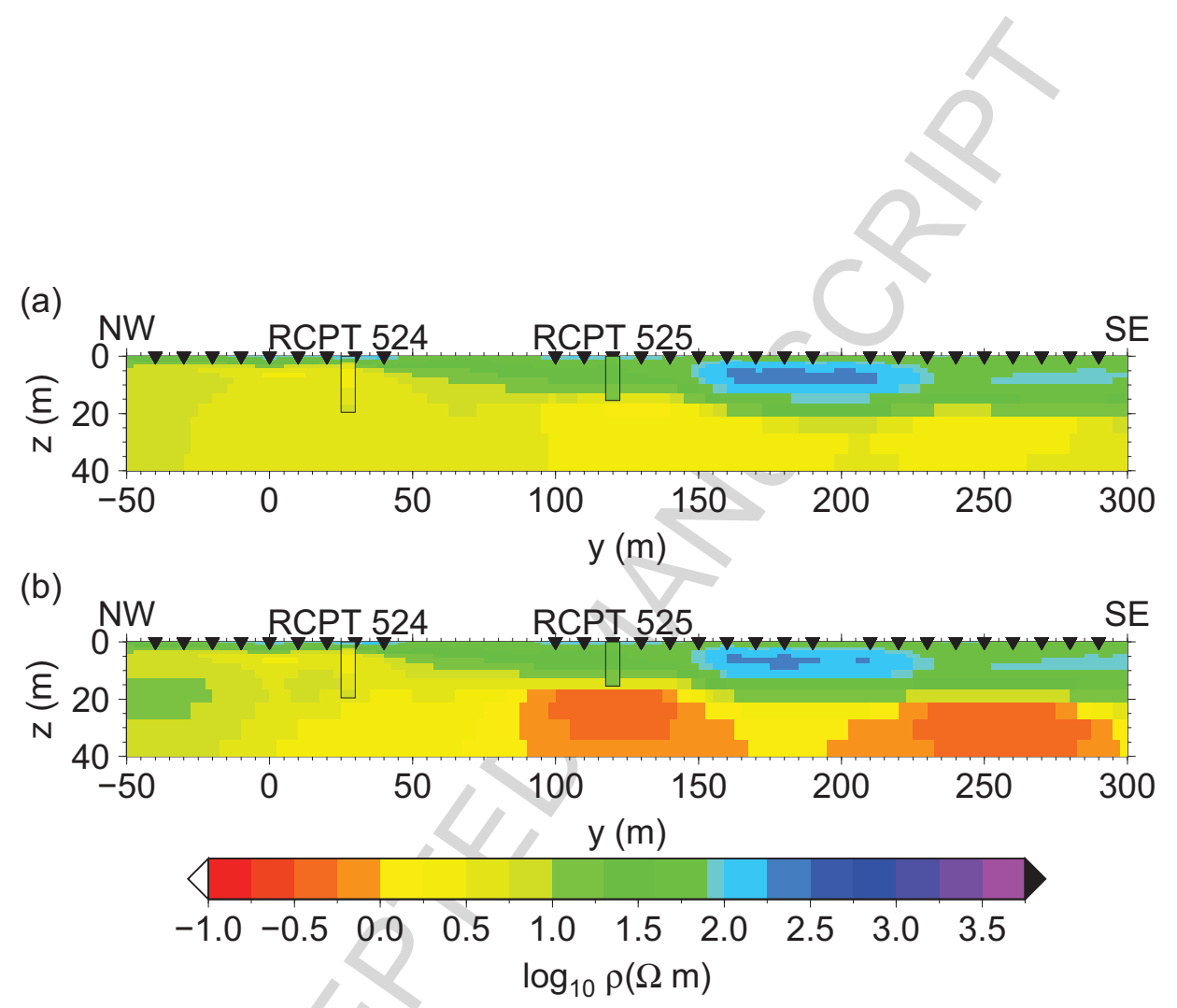

Figure 8: Resistivity models derived from (a) the 2-D inversion of RMT determinant impedance data and (b) the 2-D inversion of both RMT and CSAMT determinant impedance data (cf. Fig. 6) plotted together with RCPT logs 524 and 525. The models were computed with smoothing weights $\alpha_{y}=4$ and $\alpha_{z}=1$. The model responses fit the RMT and combined RMT and CSAMT data to RMS errors of 1.01 and 1.09, respectively. As compared to the inversion models of DCR data (Figs. 4(a) and 5(a)), a prominent conductor is discovered at $y \gtrsim 100 \mathrm{~m}$ and $z \gtrsim 20 \mathrm{~m}$. Upon inclusion of the CSAMT data in (b), this conductor at $z \gtrsim 20 \mathrm{~m}$ is more pronounced. 

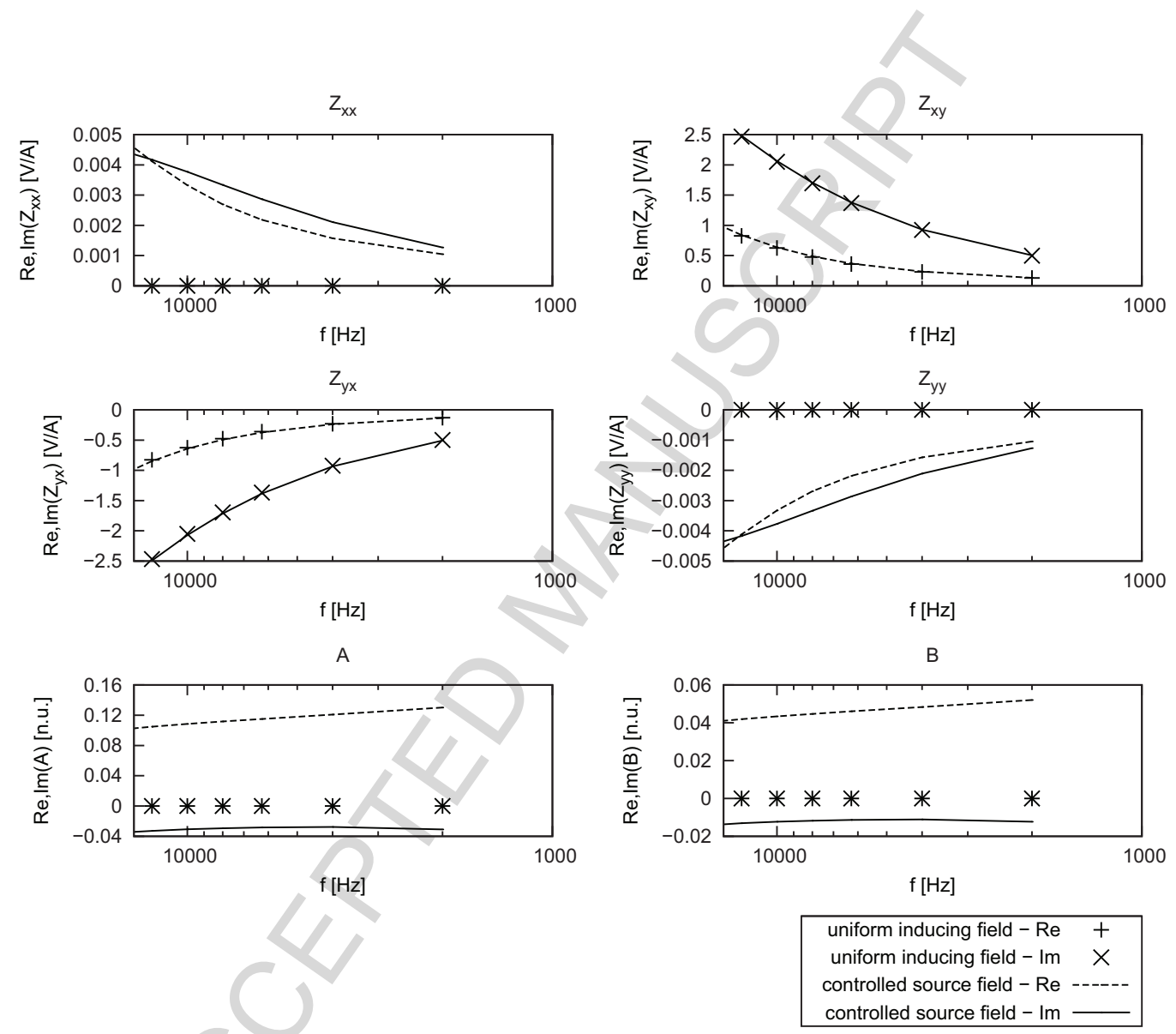

Figure 9: Evaluation of source effect on CSAMT data as computed for a 1-D resistivity section of the 2-D model in Fig. 8 (b) at the station at $y=200 \mathrm{~m}$ along the profile. The symbols and lines represent the impedance and VMTF tensor elements under the uniform inducing field assumption and with due account for the pair of HMD sources, respectively. The responses of the HMD sources were computed for the same source-receiver geometry as in the field example (cf. Fig. 2). As the off-diagonal impedance tensor elements for both source mechanisms match and the diagonal components are two orders of magnitude smaller, modelling of the CSAMT determinant impedances with a 2-D MT inverse code is reasonable. 

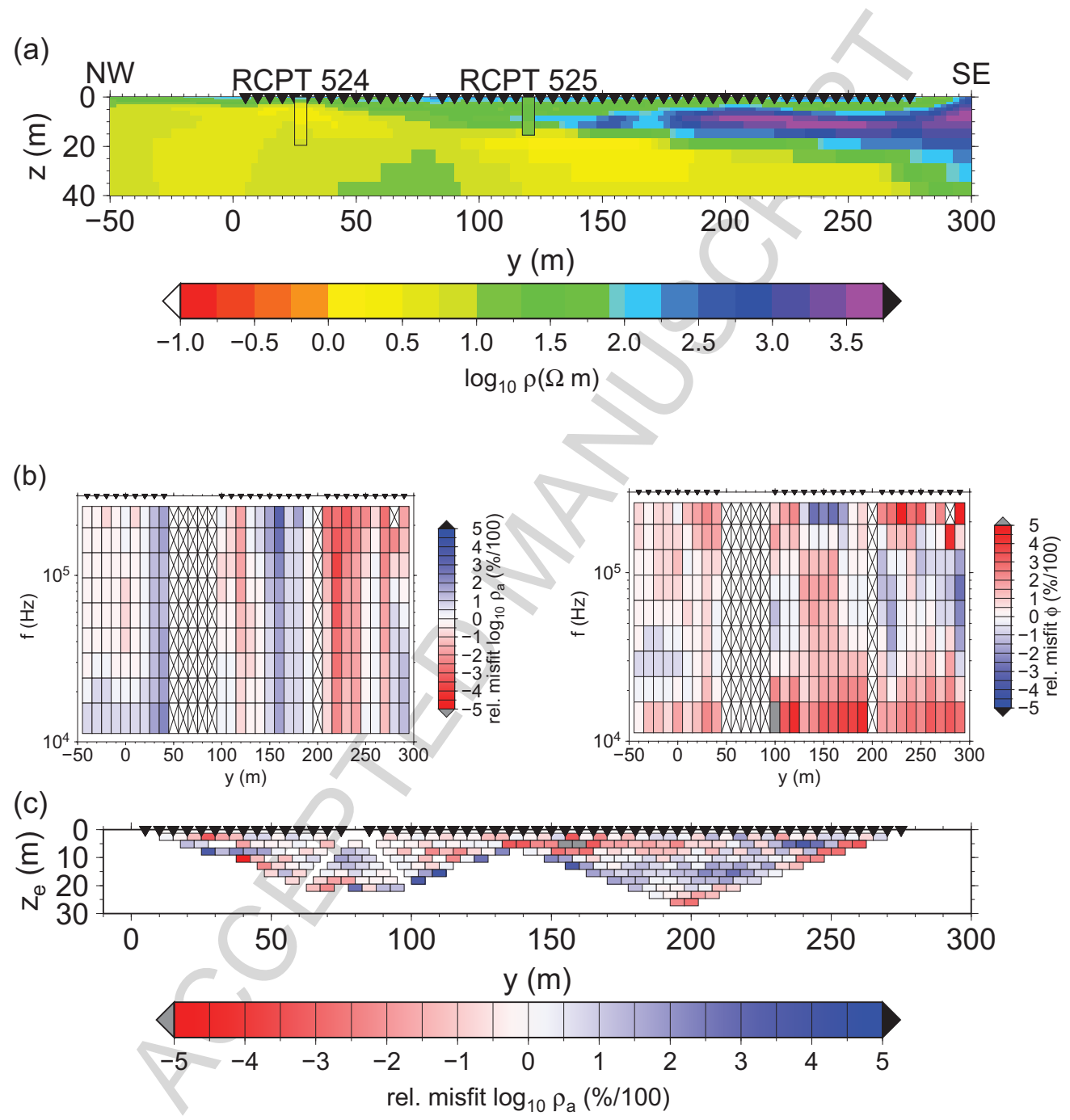

Figure 10: Joint inversion model of RMT and DCR Wenner data (a), datum-wise misfits of RMT apparent resistivities and phases (b) and datum-wise misfits for DCR Wenner apparent resistivities (c). In panel (a), black triangles mark the electrodes of the DCR Wenner array. The RMS errors of the DCR and RMT data sets are 1.44 and 1.35, respectively. The resistive structure of roughly $3000 \Omega \mathrm{m}$ between 5 and $15 \mathrm{~m}$ depth underneath the south-eastern half of the profile is more pronounced than in the individual inversions of DCR and RMT/CSAMT data. 

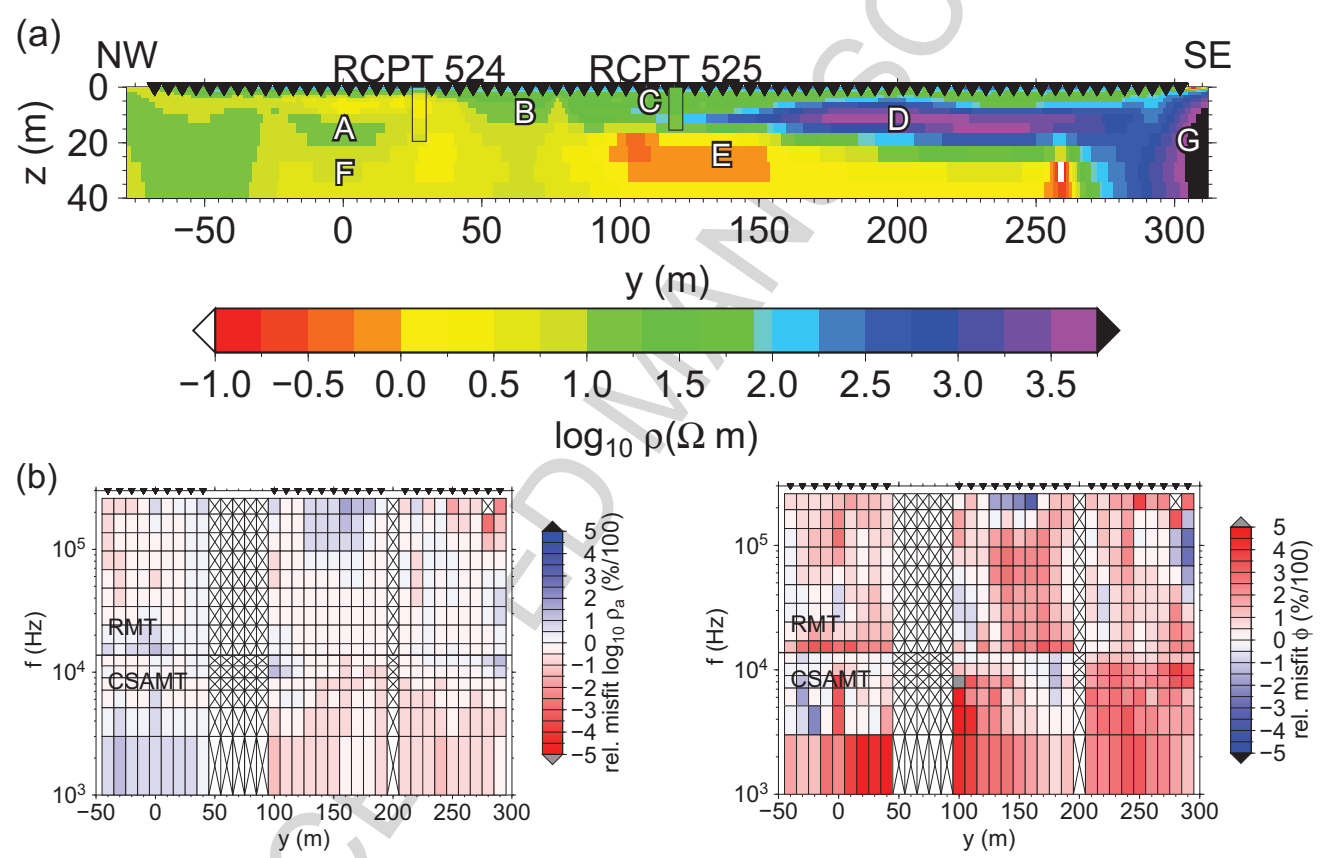

Figure 11: Joint inversion model of RMT/CSAMT and DCR gradient data (a), datum-wise misfits of RMT and CSAMT apparent resistivities and phases (b) and datum-wise misfits for DCR gradient apparent resistivities (c). In panel (a), black triangles mark the electrodes of the DCR gradient array. Labels A through G mark cells selected for subsequent model error and resolution analysis. The RMS errors of the DCR and RMT/CSAMT data sets are $\mathrm{RMS}=1.32$ and $\mathrm{RMS}=1.22$, respectively. 
(c)
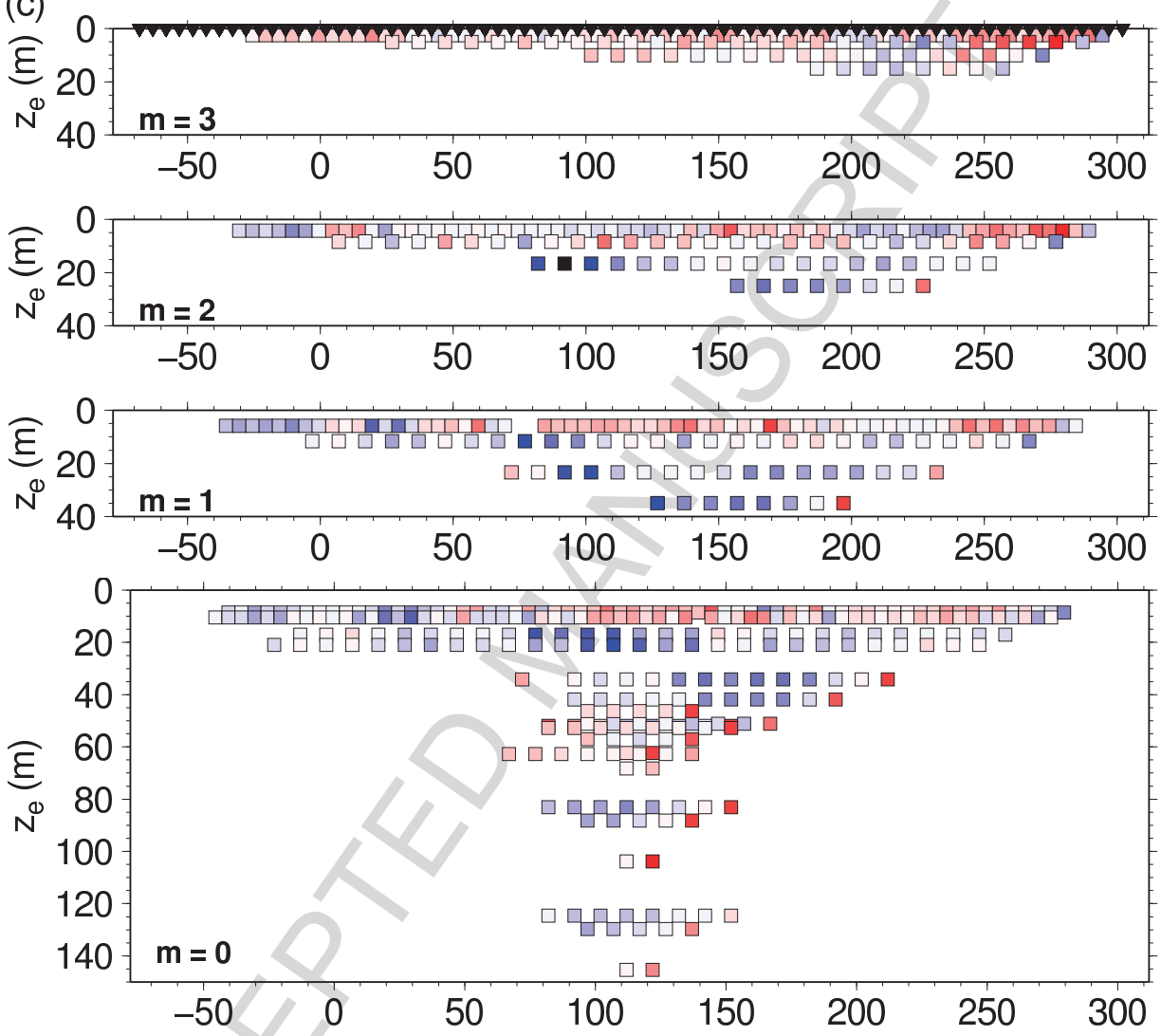

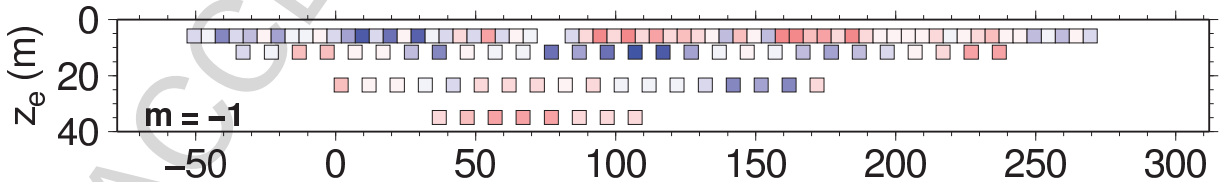

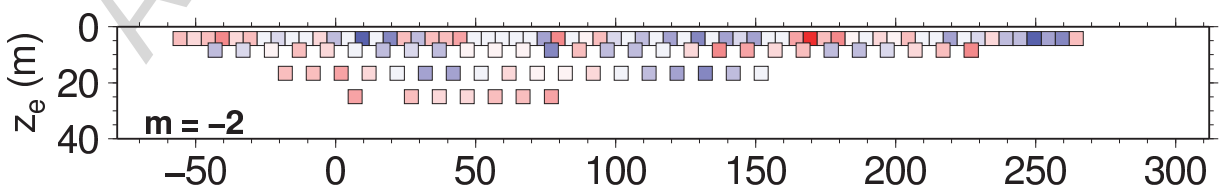

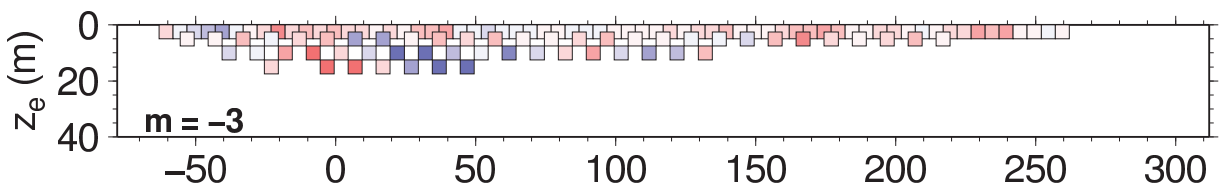

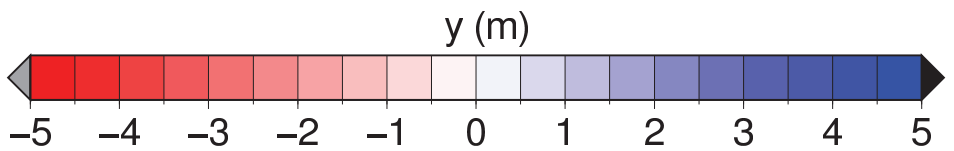

rel. misfit $\log _{10} \rho_{a}(\% / 100)$

Figure 11: $\underline{1}_{\text {continued }}$ 

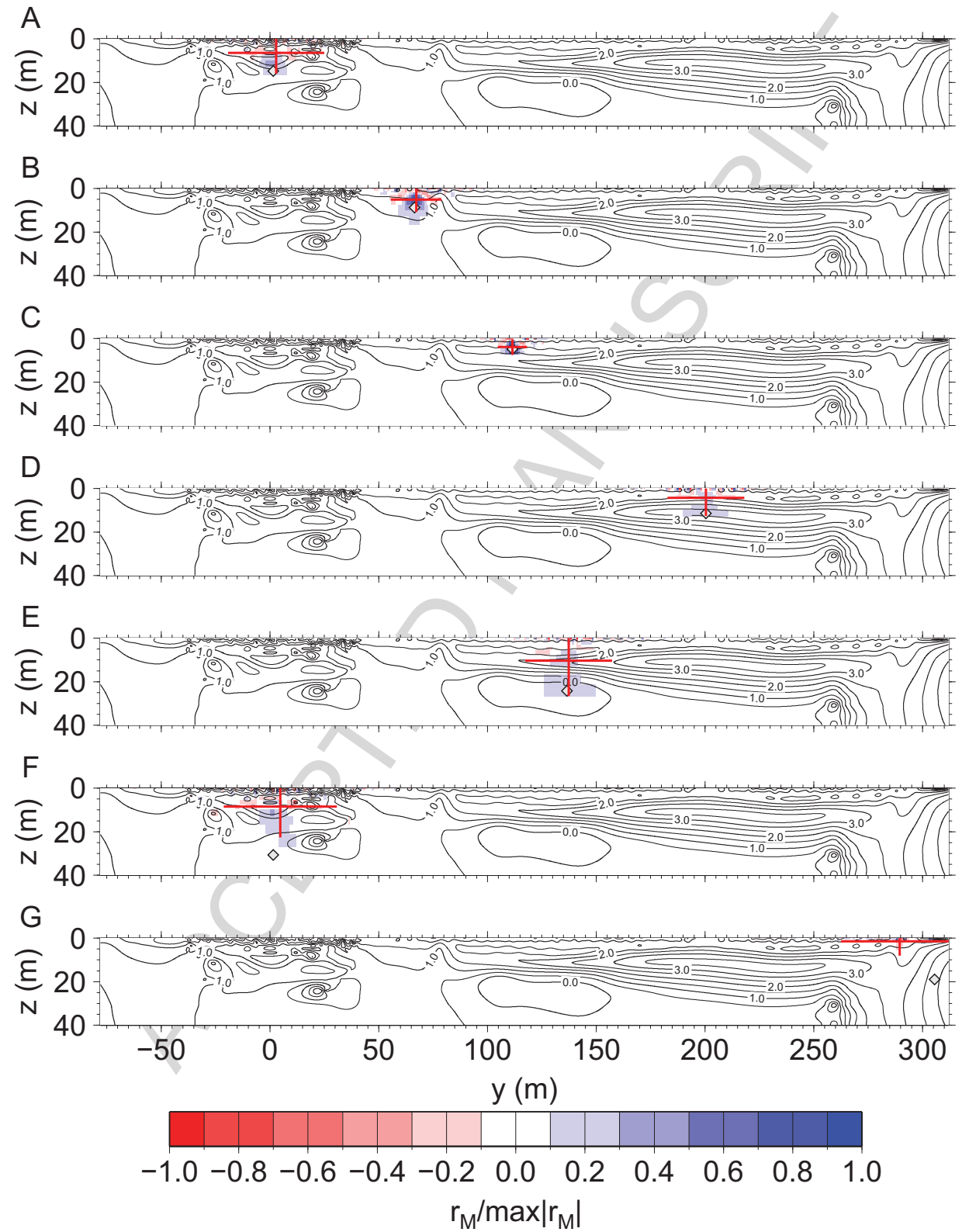

Figure 12: Resolving kernels for seven model parameters (A through $G$ ) of the inversion model in Fig. 11(a) computed with the smoothness-constrained scheme by Kalscheuer et al. (2010). The resolving kernels are scaled by their maximum moduli. The positions and sizes of the cells pertaining to the model parameters as well as the linearised model error factors $f$ are given in Table 1 . Here, the considered cells are marked by white diamonds. The red lines depict the centres of resolutigg and the horizontal and vertical resolution lengths (Kalscheuer and Pedersen, 2007). The isolines are for $\log _{10}(\rho)$ of the resistivity model in Fig. 11(a). 


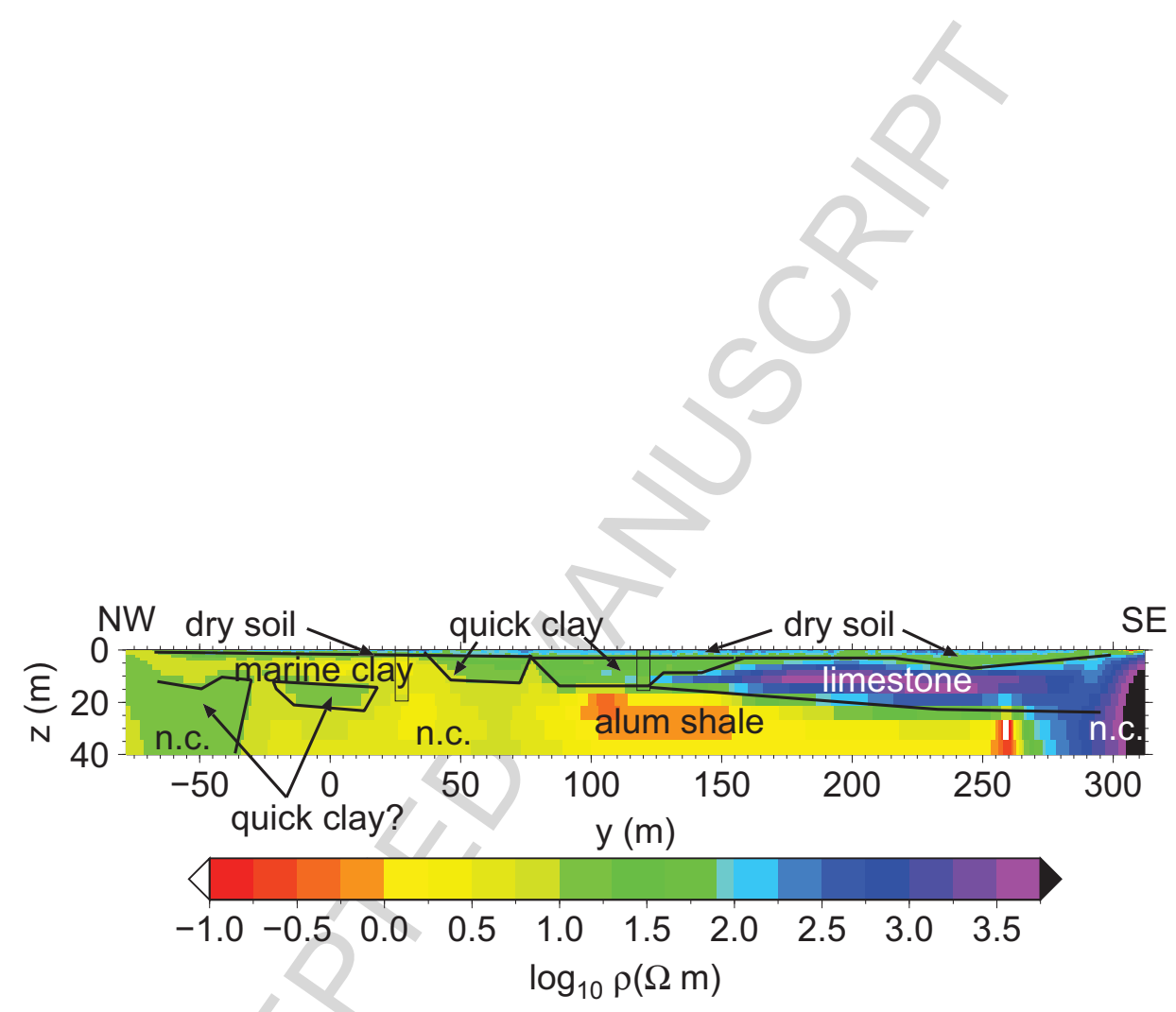

Figure 13: 2-D resistivity model from Fig. 11(a) with interpretation of structural boundaries of dry soil, marine clay, quick clay, limestone and alum shale. Parts of the model that are not constrained by the data are labelled with "n.c.". 


\section{Appendix A. Data weighting in joint inversions}

We employ the following definitions of data misfit $Q_{d}$ and weighted data misfit $Q_{d, w}$ :

$$
\begin{aligned}
Q_{d}[\mathbf{m}] & =\sum_{i=1}^{N_{d}}\left(\frac{d_{i}-F_{i}[\mathbf{m}]}{\sigma_{i}}\right)^{2}, \\
Q_{d, w}[\mathbf{m}] & =\sum_{i=1}^{N_{d}}\left(\frac{1}{w_{i}} \frac{d_{i}-F_{i}[\mathbf{m}]}{\sigma_{i}}\right)^{2},
\end{aligned}
$$

where $N_{d}$ is the total number of data, $d_{i}$ is the $i$-th datum, $F_{i}[\mathbf{m}]$ is the $i$-th forward response for the model $\mathbf{m}$ and $\sigma_{i}$ is the standard deviation of $d_{i}$. The error weights $w_{i}$ determine how the $i$-th datum influences the estimated model. If on average $\left(d_{i}-F_{i}[\mathbf{m}]\right)^{2}=\sigma_{i}^{2}$, the misfit functions assume their corresponding statistical expectation values

$$
\begin{aligned}
Q_{d}^{e}[\mathbf{m}] & =N_{d} \\
Q_{d, w}^{e}[\mathbf{m}] & =\sum_{i=1}^{N_{d}}\left(\frac{1}{w_{i}}\right)^{2} .
\end{aligned}
$$

In order to obtain a weighted misfit function that has an expectation value equal to the number of data $N_{d}$, we introduce a scaled and weighted misfit function

$$
Q_{d, s w}[\mathbf{m}]=\frac{N_{d}}{\sum_{i=1}^{N_{d}}\left(\frac{1}{w_{i}}\right)^{2}} \sum_{i=1}^{N_{d}}\left(\frac{1}{w_{i}} \frac{d_{i}-F_{i}[\mathbf{m}]}{\sigma_{i}}\right)^{2} .
$$

To assure that different data sets have the same importance in a joint inversion relatively independent of their actual numbers of data, sensitivities, non-linear natures, or qualities of data error estimates, the weights must be chosen carefully. In particular, one specific weight is assigned to all data of one particular data set, i.e. $w_{i j}=w_{j}$ for all $i=1, \ldots, N_{j}$, where $N_{d s}$ and 
$N_{j}$ designate the number of data sets and the number of data of the $j$-th data set, respectively. In terms of $N_{d s}$ and $N_{j}$, eqs. A.2 and A.5 can be re-formulated as

$$
\begin{aligned}
Q_{d, w}[\mathbf{m}] & =\sum_{j=1}^{N_{d s}} \sum_{i=1}^{N_{j}}\left(\frac{1}{w_{j i}} \frac{d_{j i}-F_{j i}[\mathbf{m}]}{\sigma_{j i}}\right)^{2} \\
Q_{d, s w}[\mathbf{m}] & =\frac{N_{d}}{\sum_{j=1}^{N_{d s}} \sum_{i=1}^{N_{j}}\left(\frac{1}{w_{j i}}\right)^{2}} \sum_{j=1}^{N_{d s}} \sum_{i=1}^{N_{j}}\left(\frac{1}{w_{j i}} \frac{d_{j i}-F_{j i}[\mathbf{m}]}{\sigma_{j i}}\right)^{2},
\end{aligned}
$$

where, for instance, $d_{j i}$ is the $i$-th datum of the $j$-th data set.

The weighting of data sets can be based on different properties, e.g.

1. number of data: the choice $w_{j}=\sqrt{N_{j}}$ yields the expectation value $Q_{d, w}^{e}=\sum_{j=1}^{N_{d s}} 1=N_{d s}$

2. sensitivities: the weighting factors are chosen as the 2-norms of the Jacobian matrices $\mathbf{J}_{j}$ of the individual data sets $j=1, \ldots, N_{d s}$, i.e. $w_{j}=1 /\left\|\mathbf{J}_{j}\right\|_{2}$ for all $i=1, \ldots, N_{j}$. The 2-norms are computed as spectral norms, i.e. as the largest singular values $\lambda_{j}^{\max }$ of the Jacobians $\mathbf{J}_{j}$ (Heath, 2002). Usage of the 2-norm appears to be justified, because the inverse problem is solved in a least-squares sense. The expectation value of the weighted misfit is $Q_{d, w}^{e}=\sum_{j=1}^{N_{d s}} N_{j} /\left(\lambda_{j}^{\max }\right)^{2}$.

3. non-linearity of the different data sets: appropriate weighting factors $w_{j}$ are determined by a trial-and-error procedure.

In all cases, one obtains an expectation value of $Q_{d, s w}^{e}=N_{d}$. In synthetic examples, Commer and Newman (2009) successfully apply data weighting schemes with weights based on the number of data of individual data sets and on the gradients of the linearised data misfit functions of individual 
data sets. For field data, we found such schemes to yield more reasonable inversion models than schemes without data weighting. However, we found these automatic schemes to be still prone to produce inversion models that over-fit one data set while not explaining the other data set in sufficient detail. For this reason, manual assignment of weights appears preferable.

For the $j$-th data set, the RMS error is computed as $R M S_{j}=\sqrt{\frac{w_{j}^{2}}{N_{j}} Q_{d, w}^{j}[\mathbf{m}]}$, where $Q_{d, w}^{j}[\mathbf{m}]$ is the sum in eq. A.6 limited to the the $j$-th data set. The cumulative RMS error for all data sets is calculated as $R M S=\sqrt{\frac{Q_{d, s w}[\mathbf{m}]}{N_{d}}}$. The expectation value of the latter quantity is 1.0 and typically is the target RMS of the inversion. It needs, however, to be verified that the choice of weighting factors $w_{j}$ is appropriate. The objective criterion is that $R M S_{j} \gtrsim 1$ for all $j=1, \ldots, N_{d s}$ and, hence, that overfitting individual data sets is avoided. 
We investigate a quick clay zone at Smorgrav, Norway, with electromagnetic methods. Individual and joint 2D inversions of DCR, CSAMT and RMT data are performed.

The 2D models show excellent agreement with resistivity cone penetration tests into marine clay and quick clay.

The joint inversions have superior constraints for a resistive limestone formation abutting the quick clay zone.

Only the CSAMT fields penetrate into deep bedrock and identify it as alum shale. 